\title{
The bioarchaeology of mid-Holocene pastoralist cemeteries west of Lake Turkana, Kenya
}

\author{
Elizabeth A. Sawchuk ${ }^{1,2}$ (D) Susan Pfeiffer ${ }^{3,4,5}$ - Carla E. Klehm ${ }^{6} \cdot$ Michelle E. Cameron $^{3} \cdot$ Austin C. Hill $^{7}$. \\ Anneke Janzen $^{2} \cdot$ Katherine M. Grillo ${ }^{8}$ Elisabeth A. Hildebrand ${ }^{1,9}$
}

Received: 15 December 2018 / Accepted: 6 August 2019 / Published online: 1 November 2019

(C) The Author(s) 2019

\begin{abstract}
Early herders in eastern Africa built elaborate megalithic cemeteries 5000 BP overlooking what is now Lake Turkana in northwestern Kenya. At least six 'pillar sites' were constructed during a time of rapid change: cattle, sheep, and goats were introduced to the basin as the lake was shrinking at the end of the African Humid Period. Cultural changes at this time include new lithic and ceramic technologies and the earliest monumentality in eastern Africa. Isolated human remains previously excavated from pillar sites east of Lake Turkana seemed to indicate that pillar site platforms were ossuaries for secondary burials. Recent bioarchaeological excavations at four pillar sites west of the lake have now yielded $\geq 49$ individuals, most from primary and some from secondary interments, challenging earlier interpretations. Here we describe the mortuary cavities, and burial contexts, and included items such as adornments from Lothagam North, Lothagam West, Manemanya, and Kalokol pillar sites. In doing so, we reassess previous hypotheses regarding pillar site construction, use, and inter-site variability. We also present the first osteological analyses of skeletons buried at these sites. Although the human remains are fragmentary, they are nevertheless informative about the sex, age, and body size of the deceased and give evidence for health and disease processes. Periosteal moulds of long bone midshafts ( $n=34$ elements) suggest patterns of terrestrial mobility. Pillar site deposits provide important new insights into early herder lifeways in eastern Africa and the impact of the transition to pastoralism on past human populations.
\end{abstract}

Keywords Pillar sites $\cdot$ Mortuary archaeology $\cdot$ Turkana Basin $\cdot$ Herding $\cdot$ Stone beads $\cdot$ Food production

\section{Introduction}

The spread of food production into eastern Africa 5000 years ago coincided with the creation of elaborate megalithic cemeteries, the first of their kind in eastern Africa and some of the earliest monumental architecture known from sub-Saharan

Elizabeth A. Sawchuk

elizabeth.sawchuk@stonybrook.edu

1 Department of Anthropology, Stony Brook University, Stony Brook, NY 11794-4364, USA

2 Department of Archaeology, Max Planck Institute for the Science of Human History, 07745 Jena, Germany

3 Department of Anthropology, University of Toronto, Toronto, ON M5S 2S2, Canada

4 Department of Archaeology, University of Cape Town, Rondebosch 7701, South Africa
Africa (Grillo and Hildebrand 2013; Hildebrand and Grillo 2012; Hildebrand et al. 2018). At least six megalithic 'pillar sites' were constructed around paleo-Lake Turkana during a period of major transition. Termination of the African Humid Period (AHP) 5300 years before present (BP) caused lake levels to drop by approximately $55 \mathrm{~m}$, altering deep water

5 Department of Anthropology and Center for the Advanced Study of Human Paleobiology, George Washington University,

Washington, DC, USA

6 Department of Anthropology, University of Colorado-Boulder, Boulder, CO 80309, USA

7 Department of Anthropology, Dartmouth College, Hanover, NH 03755, USA

8 Department of Anthropology, University of Florida, Gainesville, FL 32611, USA

9 Turkana Basin Institute, Nairobi, Kenya 
fishing habitats and exposing plains that offered new pasture opportunities for herbivores (Garcin et al. 2012; Chritz et al. 2019). Cattle, sheep, and goats were introduced into this emerging niche, ostensibly by herder populations moving out of the drying Sahara (Gifford-Gonzalez 2017; Marshall et al. 1984), marking the first food production in the region. Livestock and herding spread rapidly around Lake Turkana, bringing pastoralist groups into contact with fisher-foragers and changing the cultural landscape. In addition to monumentality, the spread of herding is linked to the emergence of new stone tool and ceramic technologies (Goldstein In Press; Grillo and Hildebrand 2013; Hildebrand et al. 2018), longdistance obsidian trade networks (Ndiema et al. 2011), and evidence for population admixture (Sawchuk 2017). Providing records of both human morphology and cultural behaviour, pillar sites are crucial to understanding how these complex biological and social processes unfolded during this dynamic period.

These mortuary sites have no known analogue within or beyond Africa (Sawchuk et al. 2018). They represent an unusual example of monumentality among mobile herders facing unpredictable circumstances and reflect unique local processes bound up in the spread of food production (Hildebrand et al. 2018). Communal cemeteries may have provided enduring landmarks on a shifting landscape, bringing herders together to form alliances, reify social networks, and exchange resources and information vital for the success of early pastoralism (Hildebrand et al. 2018; Sawchuk et al. 2018). Skeletons excavated from the pillar sites now constitute one of the largest archaeologically derived collections of human remains from eastern Africa, providing evidence relevant to population structure, behaviour, health, diet, and disease among early herders. Analysis of human remains and their mortuary contexts generates novel insights into peoples' responses to changes in their environment, economy, and society.

Our bioarchaeological analysis focuses on human remains from three pillar sites on the west side of Lake Turkana: Lothagam North (GeJi9), Lothagam West (GeJi10), and Manemanya (GcJh5). The Later Prehistory of West Turkana (LPWT) team investigated these sites between 2009 and 2014, with more limited research at a fourth pillar site, Kalokol (GcJh3). Excavations yielded the remains of at least 49 people, as well as hundreds of isolated human bone and tooth fragments. We present the mortuary contexts for these individuals, including body position, orientation, and burial goods, and we reconstruct sequences that resulted in dense interments within the central platforms of some of the pillar sites. We describe forms of personal adornment found with the burials - primarily stone and ostrich eggshell (OES) beads - as well as rarer examples of ivory, carnivore-tooth, and rodent-tooth items. Although skeletal remains are highly fragmentary as a result of environmental conditions in Turkana and burial within cobble-filled mounds, they are nevertheless informative about age-at-death, probable sex, and community health. Periosteal moulds of long bone midshafts were used to generate cross-sectional geometric (CSG) properties to reconstruct habitual movement patterns. Together, diverse bioarchaeological datasets from the western pillar sites allow us to reconsider previous hypotheses about pillar site construction and use, and, for the first time, explore the lived experiences of the people buried within them.

\section{Background}

Pillar sites are named for their linear or semi-circular arrangements of naturally occurring basalt and sandstone 'pillars', which people dragged from sources up to $2 \mathrm{~km}$ away and placed in circular or elliptical platforms of mounded stony fill. Stone circles and cairns were constructed on the margins of some pillar sites (Grillo and Hildebrand 2013; Hildebrand et al. 2011, 2018; Hildebrand and Grillo 2012). Six pillar sites are known around Lake Turkana: four on the western side, and two on the eastern, all located on imposing points overlooking the paleo-lakeshore (Fig. 1). Today, people living on the west

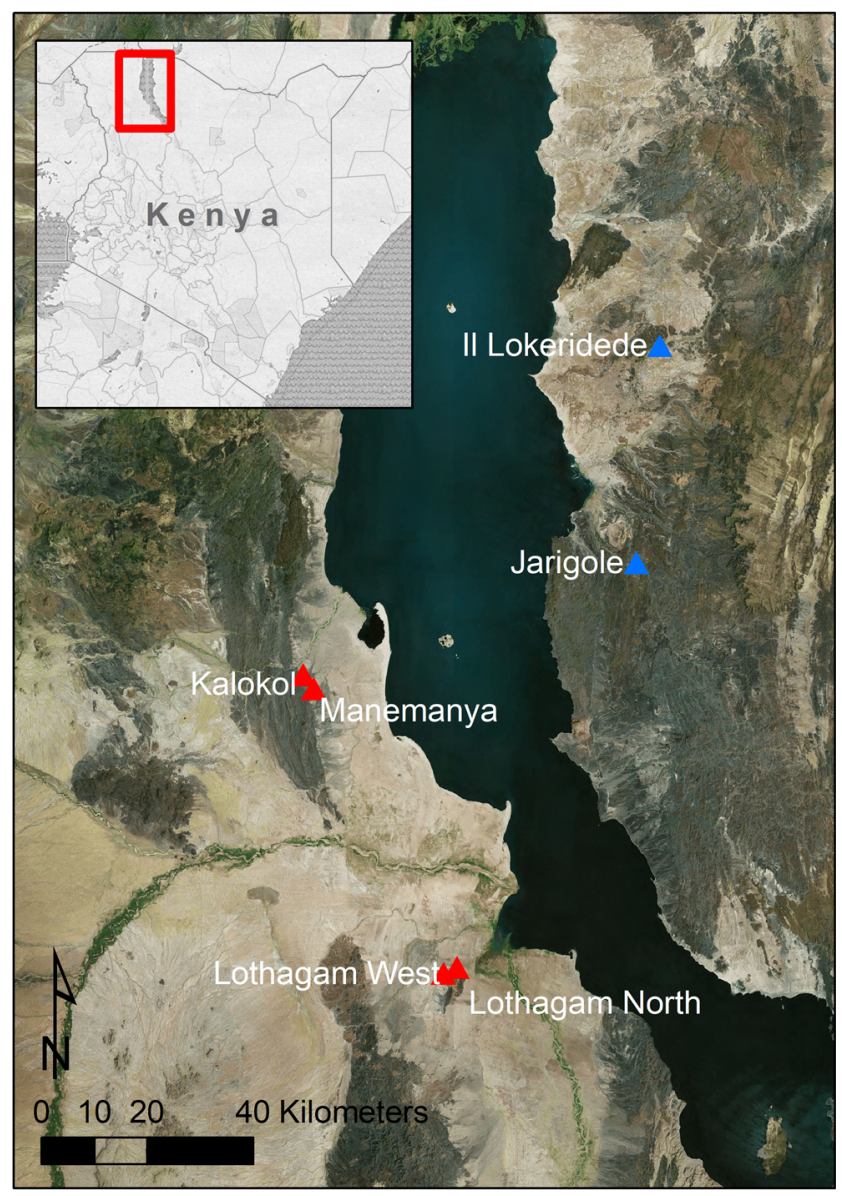

Fig. 1 Map of pillar sites around Lake Turkana. Previously excavated sites are in blue; sites described in this paper are in red. Main map (C) Earthstar Geographics SIO and Microsoft 
side of Lake Turkana call the sites namoratunga or 'people of stone' based on a legend that the pillars were human dancers turned to stone by a vengeful deity (Robbins 1972).

Megalithic sites in the basin were first explored archaeologically during the 1968-1970 Royal Geographic Society South Turkana Excavation (Gwynne 1969). The British Institute in Eastern Africa (BIEA) undertook initial excavations at Namoratunga I (also known as Lokori) between 1970 and 1976, documenting individual interments within 'stone circle graves' (Soper and Lynch 1977; see also Lynch 1978). These finds led scholars to presume that megalithic sites across the basin would likely contain burials, despite the fact that Lokori differs from most 'pillar sites' in having numerous stone circles and no pillars. Namoratunga II, also known as Kalokol (GcJh3) was the first site with pillars to be documented, via surface surveys by Lynch and Robbins $(1978,1979)$. Subsequent examples of 'pillar sites' were reported on the west side of the lake at Lothagam North (GeJi9), Lothagam West (GeJi10), and Manemanya (GcJh5) (Hildebrand et al. 2011; Hildebrand and Grillo 2012), and on the east side of the lake at Jarigole (GbJj1) and Il Lokeridede (GaJi23) (Githinji 1999; Koch 1993, 1994; Nelson 1995). Other potential sites include GbJj4 (Kamau 1991) and an unconfirmed site in the Suguta Valley (Hildebrand et al. 2011).

Jarigole was the first pillar site (sensu stricto - having a platform and upright pillars) to be excavated, by the Koobi Fora Field School 1986-1996. Nelson (1995:52) ${ }^{1}$ reported numerous overlapping burial pits in Jarigole's central mound, with bones and artefacts 'mixed into the fill as new burials intruded into and scattered the contents of the old'. Lower down, excavators found a primary inhumation of a tighly flexed elderly individual $60-65 \mathrm{~cm}$ below the surface of the mound, overlain by large rocks. Other rock clusters were noted but not excavated, raising the possibility that the site might contain deeper primary burials. Excavators did not reach bedrock or sterile deposits before worked at the site ceased in 1996.

Il Lokeridede, $\sim 30 \mathrm{~km}$ north of Jarigole and $\sim 2 \mathrm{~km}$ from the habitation site Dongodien (GaJi4), is a smaller pillar site marked by large sandstone slabs (Githinji 1999; Koch 1994; Koch et al. 2002). Limited excavations there also revealed platform mortuary deposits, interpreted as containing secondary burials (see Githinji 1999).

Based on these preliminary findings, Koch $(1993,1994)$ and Nelson (1995) proposed a Jarigole Mortuary Tradition/ Ossuary Complex encompassing all pillar sites within the Turkana Basin. The complex, attributed to early herders,

\footnotetext{
${ }^{1}$ Note: Several versions of Nelson 1995 are in circulation: (a) the original print version of the Kenya Past \& Present article, (b) a PDF version, (c) HTML versions of which one is currently available at http://www.chaz.org/Arch/ Turkana/Jarigole/Jarigole.htm, and (d) a Word version. Not all versions of (b), (c), and (d) downloaded or exchanged between colleagues over the years have the entirety of information presented in (a). We are using (a), the original print version.
}

was thought to represent two stages of mortuary activity: a hypothetical primary-burial or other treatment that entailed defleshing, disarticulating, and breaking of human remains, followed by secondary burial of fragmentary bones and grave goods in a communal ossuary. Pillar sites were seen to represent the second stage of activity. Koch and Nelson's hypotheses - that pillar sites were created by early herders and served as ossuaries for commingled, secondary burial remains - were not resolved by fieldwork at Jarigole and Il Lokeridede. However, their descriptions of the material culture found at these pillar sites, particularly Nderit ceramics, obsidian-based lithic assemblages, and OES/stone beads, established a connection with habitation sites such as Dongodien (Barthelme 1977, 1985) and formed important baselines for the evaluation of other pillar sites.

Between 2009 and 2014, LPWT initiated research at four pillar sites on the west side of the lake: Lothagam North, Lothagam West, Manemanya, and Kalokol (Grillo and Hildebrand 2013; Hildebrand et al. 2011; Hildebrand and Grillo 2012) (Fig. 2). Test excavations at these sites provided radiocarbon dating samples that - combined with dates from Jarigole collections and published age determinations for Il Lokeridede (Koch et al. 2002) - provided the first absolute chronology for pillar sites around the lake. Their chronological overlap with early pastoral habitation sites near Lake Turkana's paleoshore (4964-4000 cal BP) (Barthelme 1985; Marshall et al. 1984) suggests pillar site construction was coeval with the introduction of herding (Hildebrand and Grillo 2012).

Chronological relations within and between pillar sites raise intriguing points. Three extremely precise dates indicate that Lothagam North, Lothagam West, and Manemanya all saw use within a 43-year period (4868-4825 cal BP), and use of Jarigole during this interval is also likely (Hildebrand and Grillo 2012). Such tight contemporaneity of use lends support for Nelson and Koch's hypothesis of a basin-wide monumental tradition. Construction and use of pillar sites covered a minimum temporal range of 4853-4541 BP (312 years). The maximum range of use runs from 5270 to $4102 \mathrm{cal} \mathrm{BP}$ (1168 years) but includes one late 'outlier' date from each of Manemanya, Kalokol, and Lothagam North sites, which might represent subsequent additions or renewal of activities (Hildebrand and Grillo 2012; Hildebrand et al. 2018). Without these outliers, pillar sites' maximum temporal range runs from 5270 to $\sim 4500$ cal BP ( $~ 770$ years). Thus, the main expression of this monumental tradition appears to have spanned somewhere between three and seven centuries.

Excavations also revealed inter-site variability in architecture and mortuary and material cultural practices. Although all six sites possess pillars, the number, orientation, and positioning of the stone columns differ (Hildebrand et al. 2011). Associated cairns are found at Lothagam North $(n=6)$, Lothagam West $(n=9)$, and Kalokol $(n=2)$ but not at 
Fig. 2 Orthophotographs of a Lothagam North, b Lothagam West, c Manemanya, and d Kalokol. All orthophotographs are derived from aerial images recorded via drone and Ground Control Points (GCPs) recorded via total station, processed in Photoscan Pro. Image by A.C. Hill
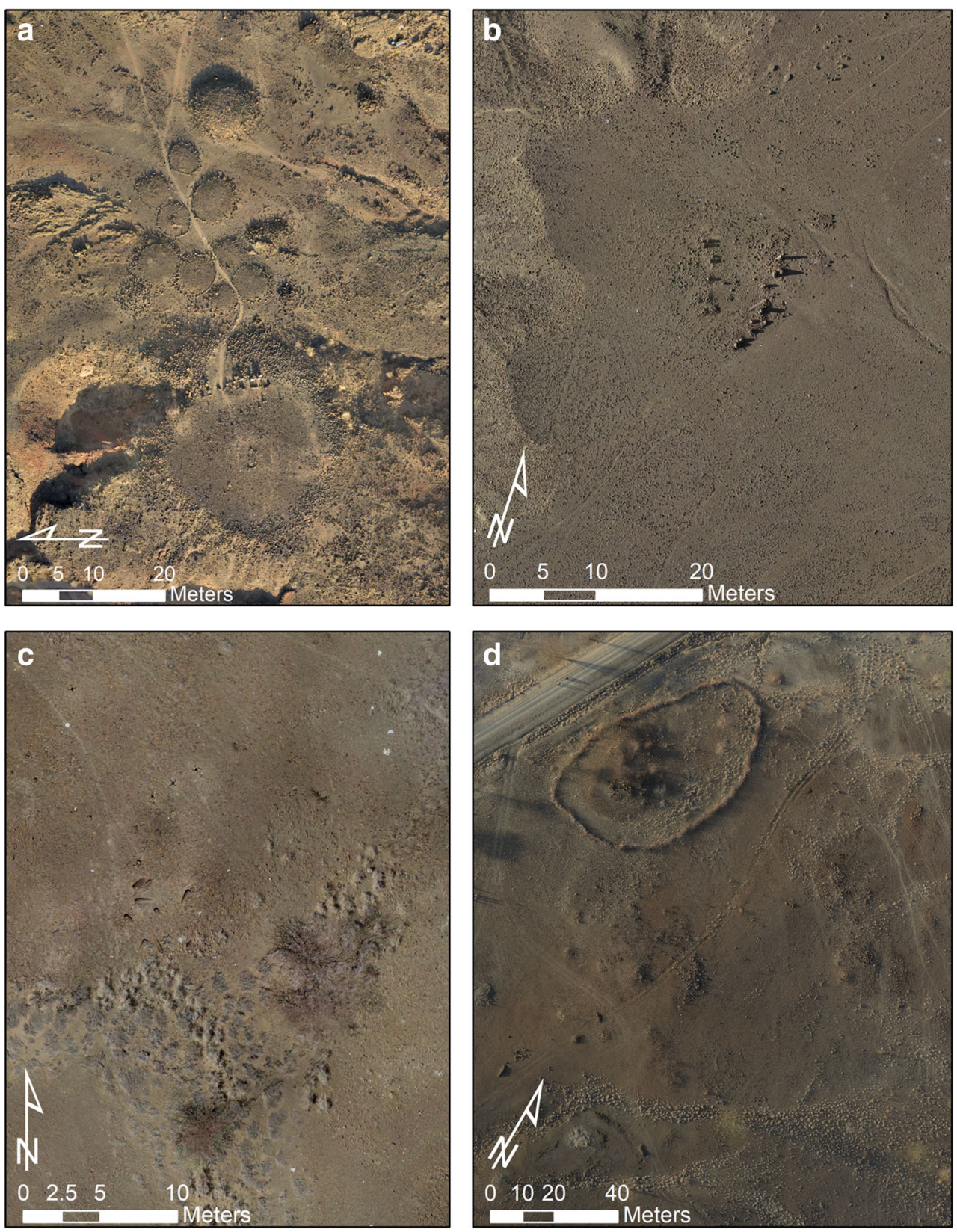

Manemanya. Lothagam North possesses nine stone-ringed circles in addition. Material culture - notably the presence/ absence of Nderit pottery and stone tool raw material preferences - and mortuary patterns vary from site to site. Caprine remains and a zoomorphic bovine palette from Lothagam North (Hildebrand et al. 2018: Fig. 3), together with earlier discoveries of ceramic cattle and sheep figurines from Jarigole (Grillo and Hildebrand 2013: Fig. 3; Nelson 1995), provide additional support for the sites' architects being herders. However, we do not know the extent to which people engaged in pastoral production (Grillo and Hildebrand 2013; Hildebrand et al. 2018).
Drawing on new bioarchaeological findings, we can now re-evaluate earlier hypotheses about how pillar sites were constructed and used. For Lothagam North, Lothagam West, and Manemanya, we report funerary practices and associated artefacts. We also explore the biocultural impact of environmental, economic, and social transitions on early herder populations around Turkana as reflected in aspects of human biology. Because excavations at Lothagam North were most extensive, we present results for this site separately from Lothagam West and Manemanya. However, overarching patterns in the mortuary and osteological data provide important information on the people who built these three sites and are pertinent to 


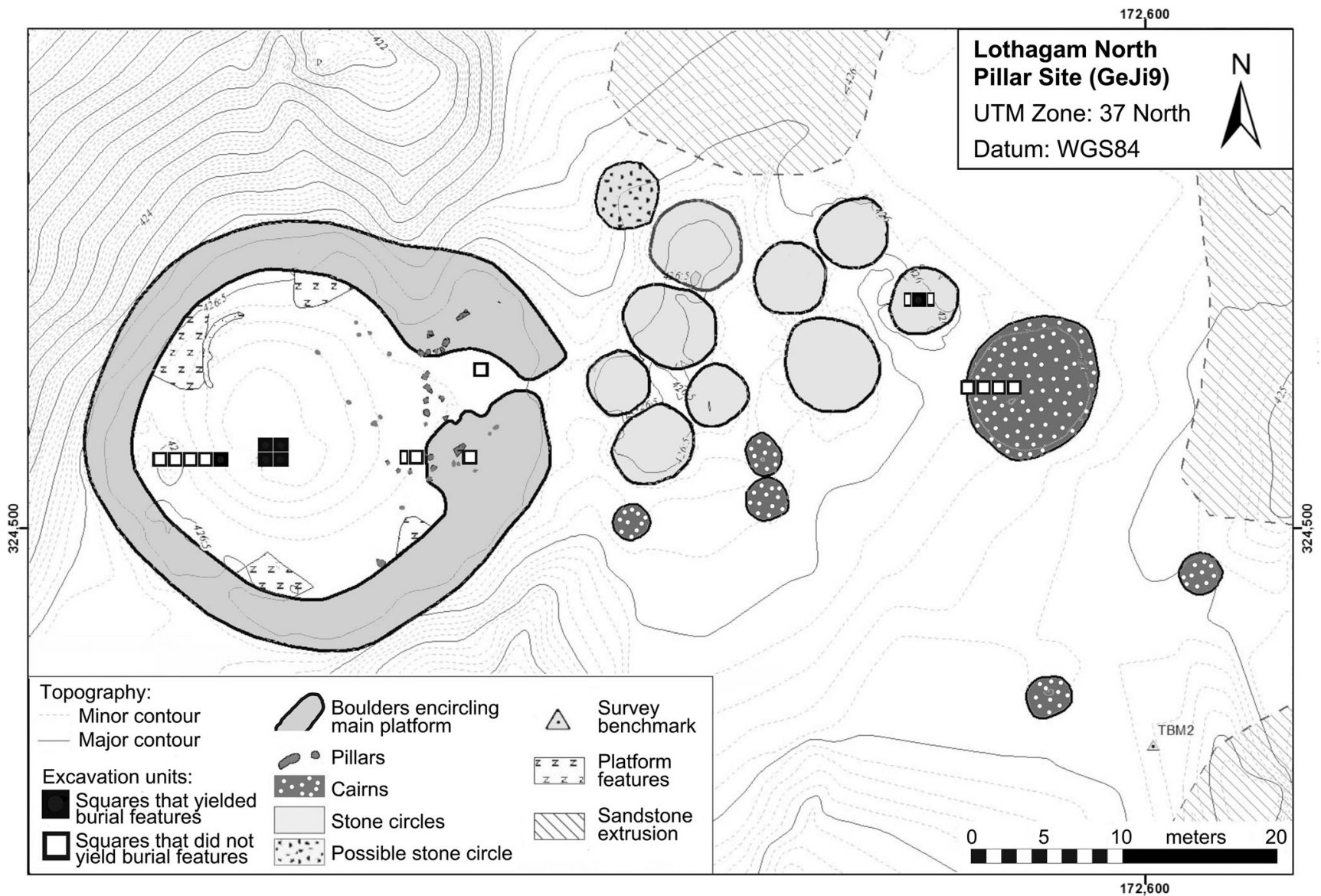

Fig. 3 Excavation plan map of Lothagam North indicating areas with human remains (adapted from map by B. Kimeu)

questions about pillar site function and the degree of cultural homogeneity (Grillo and Hildebrand 2013). We consider whether pillar sites represent a cohesive mortuary tradition, and whether they reflect broadly consistent cultural and burial practices. As little comparative information exists regarding other archaeologically known herding populations within and beyond eastern Africa, this new skeletal collection will be important for future research on the impacts of the transition to pastoralism.

\section{Methods}

Burials were first encountered at Lothagam North and Manemanya in 2009 but were not excavated because a bioarchaeologist was not present at the time (Hildebrand et al. 2011). Bioarchaeological excavations proceeded between 2012 and 2014 and targeted mortuary deposits at Lothagam North, Lothagam West, Manemanya, and Kalokol. At Lothagam North (Fig. 3), a $2 \times 2 \mathrm{~m}^{2}$ unit in the central platform and a $1 \times 5 \mathrm{~m}^{2}$ trench toward its western edge both yielded burial deposits; three other $1 \times 1 \mathrm{~m}^{2}$ units near the eastern edge of the platform did not yield human remains.
Among architectural features away from the platform to the east, a $2 \times 1 \mathrm{~m}^{2}$ unit in the centre of one of the stone circles yielded human remains, but $1 \times 4 \mathrm{~m}^{2}$ trench into the side of a large cairn to the east stopped short of the likely location of mortuary deposits. Figure 4 illustrates excavations at Lothagam West, Manemanya, and Kalokol. We targeted three areas at Lothagam West: one $1 \times 3 \mathrm{~m}^{2}$ trench into a cairn on the edge of the platform, one $1 \times 2 \mathrm{~m}^{2}$ unit in the centre platform, and another unit on the north edge of the platform by a cluster of pillars; the first two units yielded human remains. Excavations at Manemanya focused on a $2 \times 2 \mathrm{~m}^{2}$ trench (stepping down to a $1 \times 2 \mathrm{~m}^{2}$ unit) in the centre of the platform that exposed two burials near the base of the platform deposits. A previously excavated unit on the southeast margin of the site did not yield human remains (Hildebrand et al. 2011). At Kalokol, a cairn feature on the northern extent of the site yielded probable human remains that were not excavated. Two previous $1 \times 1 \mathrm{~m}^{2}$ units on the southeast margin of the platform did not yield burial deposits. General excavation and spatial documentation methods for all these sites are described by Hildebrand et al. (2011, 2018).

Bioarchaeological recovery methods combined standard field practices of exposure, mapping, and documentation 


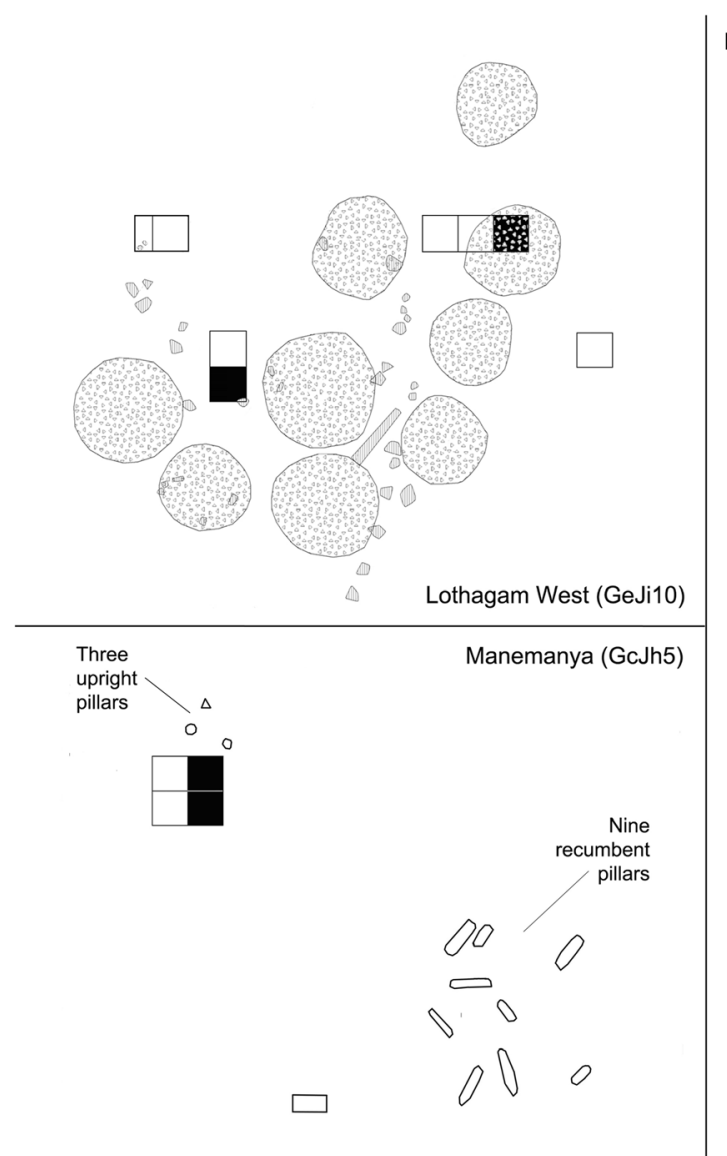

Fig. 4 Excavation plan maps of Lothagam West (upper left), Manemanya (lower left), and Kalokol Pillar Site (right) indicating areas with human remains. The Lothagam West map is based on 2012 total station field mapping by B. Kimeu, during which we noticed more and larger cairns than during our brief 2009 observations reported in Hildebrand et al.

through images and notes with adjustments developed in response to the intense sunlight and strong winds, complex stratigraphy, and poorly preserved remains. Conditions after interment at all three sites - including poor water drainage, organic sediment, consistently warm-to-hot temperatures, and pressure from the overlying boulder and cobble fill-led to de-mineralisation of bones and tooth roots. Once exposed to dry air and sunlight during excavation, bone would crack and delaminate within minutes. To compensate, excavators worked quickly after initial exposure, kept remains shaded, and stabilized bone as needed with consolidant (Butvar-98, thinned with acetone).

Upon discovery, burials were shaded with UV umbrellas and cleaned with fine brushes to define the limits of the feature and determine completeness, body position and orientation, and associated features. If preservation was fair to moderate, samples for ancient DNA were collected directly from field contexts using gloves, mask, and alcohol-swabbed implements to minimize contamination. We applied consolidant selectively to in situ skeletal fragments in order to preserve their morphology, allowing them to dry while shaded.

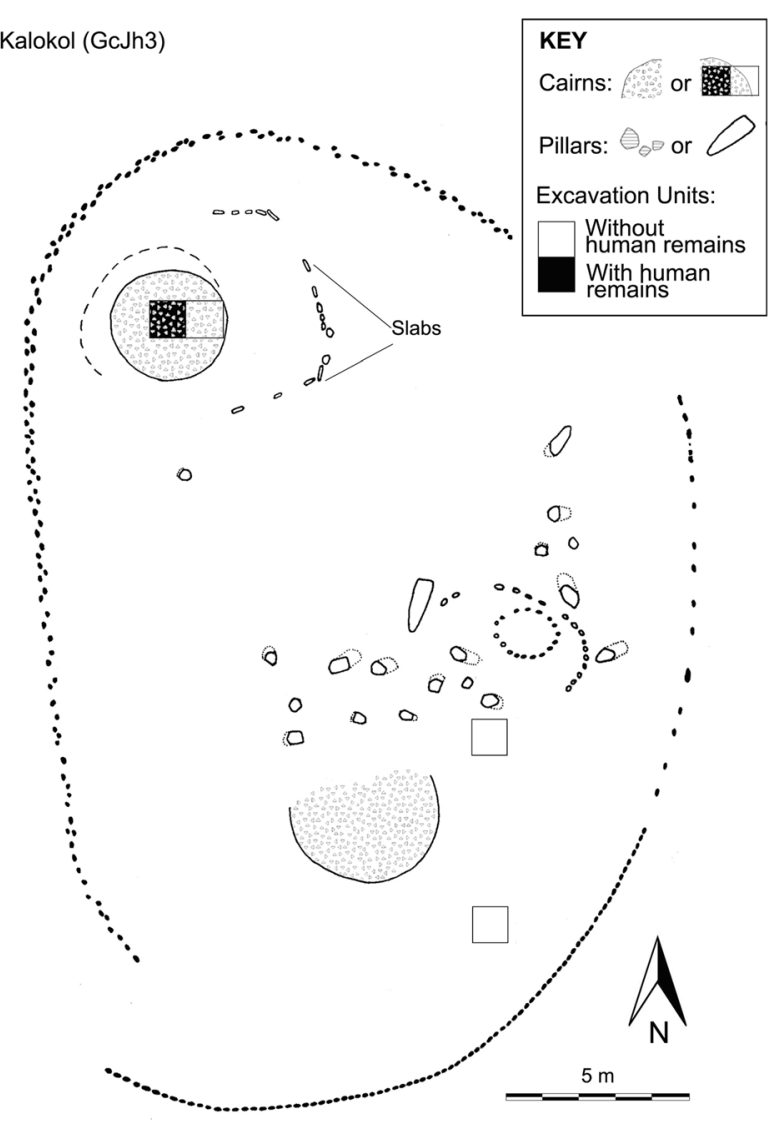

2011. The Manemanya map is an updated version of the map presented in Hildebrand et al. 2011:195. The Kalokol Pillar Site map integrates information from maps by Soper (1982:148), Hildebrand et al. (2011:193), and 2012 total station field mapping by B. Kimeu. All maps are to the same scale

Consolidant was not applied to small fragments, teeth (mainly crowns, the roots having deteriorated), nor associated artefacts (e.g., adornments).

We recorded the perimeter of each body (where distinct) as well as the margins of discernable burial pits using either a Leica or Nikon total station. We also piece-plotted selected artefacts within the burial fill. In 2013 and 2014, sets of images were recorded for $3 \mathrm{D}$ photogrammetric processing at regular intervals as well as at the end of the excavation. Ground Control Points (GCPs) were recorded for photogrammetry processing using the total station and all image sets were processed using Photoscan Pro.

Secondary bundle burials - disarticulated arrangements of predominantly long bones often representing multiple individuals - were documented and removed following a procedure in which each bone was numbered, and photographically documented from a single point a short distance from the unit before removal (Williamson et al. 2003). This permitted subsequent determination of minimum number of individuals (MNI) and osteobiographic analysis after the feature was fully excavated. Given the dense, overlapping nature of burials in 
the central platform's mortuary cavity, recovery focused on remains lying entirely within the excavation units. Skeletal elements visible in the walls were documented but not removed.

Artefacts associated with the burials were piece-plotted by total station, then catalogued at the Turkana Basin Institute (TBI) Turkwel facility. Point provenience data were then plotted in ArcGIS. Stone and bone beads associated with specific individuals were photographed in situ, then cross-checked against total station data. Stone and mineral raw materials of the beads and pendants were identified using a combination of visual characteristics, measurement of the specific gravity of a representative sample of the bead artefacts, and archaeometric methods including Raman spectroscopy, XRD, and SEMEDX (described in Hildebrand et al. 2018 Supplementary Information). This identification includes major classifications (e.g. chalcedony) and sub-categories (e.g. carnelian, or deep-red-to-red chalcedony) as well as reconstructions of the bead manufacture. Ostrich eggshell (OES) beads at Lothagam North number in the thousands and could not always be clearly attributed to individuals but were qualitatively noted within burials. At Lothagam North, OES beads were so numerous that representative samples from certain units/levels were counted to estimate the total number of beads excavated. At Manemanya and Lothagam West, beads were counted fully from all excavation contexts. Although most of the highly fragmentary faunal remains may have been deposited inadvertently as part of the burial fill, several burials included either animal-tooth adornments or near-complete faunal elements that we interpret as mortuary goods. These faunal remains were identified to element and taxon.

After cleaning, reconstruction, and further consolidation (as appropriate, and with tissue set aside for biomolecular analyses), skeletal analysis methods included assessment of age at death, sex, and other osteobiographical details using established methods (AlQahtani et al. 2010; Buikstra and Ubelaker 1994; White et al. 2011). Juvenile ages at death were determined from dental development (AlQahtani et al. 2010) and epiphyseal fusion (White et al. 2011). Adulthood was determined by presence of third molars, epiphyseal fusion, and features like overall bone size, texture, and cortical thickness. Adult age at death was estimated from agerelated osteological changes (e.g. at the pubic symphyses, auricular surfaces, and sternal rib-ends, as available) in conjunction with indicators such as degree of dental wear, cranial suture obliteration, and presence of degenerative joint disease (DJD). Wherever possible, adults were grouped into younger (18-30 years), middle aged (30-50 years), and older (50+ years) age categories. Adult sex was determined by pelvic and cranial morphology following standard practice (Buikstra and Ubelaker 1994). Where possible, stature and body mass estimates were based on a combination of in situ long bone measurements, maximum femur head diameter, and maximum metacarpal lengths (per McHenry 1992; Meadows and Jantz 1992; Ruff et al. 1991; Trotter 1970; Trotter and Gleser 1952).

Where preservation permitted, individuals were assessed for pathological changes such as cribra orbitalia, porotic hyperostosis, DJD, dental caries, enamel hypoplastic defects, antemortem tooth loss, periodontitis, and abscessing. Observations were compromised by poor preservation, particularly of cranial material. Limitations arising from poor preservation also affected our capacity to systematically assess skeletal indicators of trauma, disease, and behavioural indicators like presence of squatting facets. Skeletal and dental measurements and non-metric data were collected following standard protocols (Buikstra and Ubelaker 1994; Hillson 2005; Turner et al. 1991). The skeletal collections from Lothagam North, Lothagam West, and Manemanya pillar sites are curated at the TBI-Turkwel facility in Turkana County, Kenya.

Thirty-three adult long bones were sufficiently well preserved to make periosteal casts of estimated mid-shafts for biomechanical analyses. A mould was also made of a femur from the primary burial excavated from Jarigole, curated at the National Museums of Kenya (NMK) in Nairobi. We used Exaflex Heavy Body silicone impression material to create midshaft diaphyseal ring moulds of femora, tibiae, humeri, ulnae, radii, and clavicles. Upper limbs were moulded bilaterally and lower limbs unilaterally, assuming symmetry of lower limb loading (Auerbach and Ruff 2006). Anatomical planes of orientation were marked to preserve correct orientation for digitisation on an Epson flatbed scanner. We estimated the limits of the periosteal boundary by manually tracing along the edge of the digitised moulds using a drawing tablet. Endosteal boundaries were not analysed; however, CSG properties obtained solely from periosteal contours are accurate (Stock and Shaw 2007; Macintosh et al. 2013). Images were analysed using ImageJ platform (Rasband 1997-2012) with the Moment Macrov1.3 plug-in (Ruff 2006) to estimate maximum $\left(I_{\max }\right)$ and minimum $\left(I_{\min }\right)$ bending strength.

The ratio of maximum to minimum bending strengths $\left(I_{\max } / I_{\min }\right)$ reflects diaphyseal shape by comparing two nonfixed axes, indicating a bone's capacity to resist bending forces (Ruff 2008). Because different activities incur various degrees of long bone shaft bending, comparisons of $I_{\max } / I_{\min }$ may suggest differences in the types of physical behaviours undertaken in life. The incomplete nature of the skeletal elements precludes analyses that rely on anatomically fixed axes, as well as CSG properties that must be standardized to body size or bone length before conducting comparisons.

Given the dearth of Holocene eastern African comparative data, pillar site individuals were compared to CSG properties from multiple southern African Later Stone Age (LSA) groups: hunter-gatherers inhabiting Mediterranean environments along the Cape Coast, hunter-gatherers involved in some herding in semi-arid areas of the Central Interior, and 
hunter-gatherers more heavily engaged in herding in arid areas of the Namib Desert. Cape Coast $I_{\max } / I_{\min }$ values were obtained using the methodology described above. Data for the Central Interior and Namib Desert southern African groups were obtained using 3D surface scans (Cameron and Stock 2018), results from which are comparable to those obtained with periosteal moulds (Davies et al. 2012; Cameron and Pfeiffer 2014). Humerus, femur, and tibia data were available for all three southern African groups, whereas clavicle, radius, and ulna data were only available for Cape Coast individuals. Comparisons among groups were performed using KruskalWallis ANOVAs, with Mann-Whitney $U$ tests for subsequent pairwise comparisons $(\alpha=0.05)$.

\section{Results}

\section{Mortuary sequence}

Pillar sites appear to have functioned as mortuary repositories: all have some combination of primary and/or secondary burials in platforms, stone circles, and/or cairns, and none have evidence for habitation or other activity centres. However, preliminary excavations suggest the scope, density, and architecture of the burial deposits vary among the sites.

\section{Lothagam North}

Extensive excavations at Lothagam North allowed for reconstruction of the burial sequence for deposits concentrated in the central platform (Grillo and Hildebrand 2013; Hildebrand et al. 2018; Hildebrand and Grillo 2012). The site's construction began with the removal of $\sim 120 \mathrm{~m}^{2}$ of Holocene beach sands to create a deep cavity ringed with boulders and reinforced by sandstone slabs. The first burials were placed in pits dug into the soft sandstone bedrock. After the floor space of the cavity was exhausted, subsequent bodies were added above the pits in various positions and orientations. Based on remote sensing of the mortuary cavity and the number of individuals recovered from a $2 \times 2 \mathrm{~m}^{2}$ unit, the platform contains an estimated minimum of 580 burials (Hildebrand et al. 2018). Positions of the burials documented within this unit illustrate the density of interments within the central platform (Fig. 5).

Platform fill between the burials contained high densities of artifacts, including lithics, ceramic sherds and a ceramic figurine fragment, stone and OES beads, and other adornments. While some artefacts (e.g. many of the stone beads) seem to have been deliberately included as part of a specific burial, others (e.g. highly fragmented pottery sherds that do not refit into whole vessels) appeared to be incorporated into the fill in a more general way (Hildebrand et al. 2018 Supplementary Information). Burial activities stopped before the cavity was completely full, and 30-50 cm of rocky sediment was added, creating a mounded surface capped with rounded, uniformly sized basalt pebbles. Pillars were emplaced within the uppermost cap deposits.

Bodies placed in the central platform did not follow a single funerary convention (Table 1). Two-thirds of the burials were primary; the others were secondary 'bundle burials' or features that were too poorly preserved to categorize by burial type. Among primary burials, the bodies were oriented in multiple directions, apparently placed as space permitted: east-west with the head at the east $(n=11)$, north-south $(n=$ $6)$, northeast-southwest $(n=5)$, south-north $(n=4)$, southeastnorthwest $(n=2)$, southwest-northeast $(n=1)$, and west-east $(n=1)$. Skeletons with preserved cranial remains were observed to be facing north $(n=8)$, west $(n=6)$, east $(n=4)$, south $(n=2)$, northwest $(n=1)$, northeast $(n=1)$, and southeast $(n=1)$. Individuals tended to be flexed on one side, with arms and legs tightly contracted toward the torso and hands in front of the face. Many individuals were highly flexed to a degree that would have been unnatural in life, suggesting bodies may have been bound, wrapped, or shrouded in this position prior to the onset of rigour mortis. Bundle burials were commonly found to be linear arrangements of predominantly long bones representing parts of one or more individuals. We did not observe spatial or funerary patterning with respect to age, sex, or placement of the bundles-men, women, and children who decomposed elsewhere were placed near primary interments. Red ochre staining was occasionally observed on bones within both primary and secondary burials. None of the remains showed evidence of burning or cremation.

Once placed, primary and secondary burials were covered with rocky sediment that often included a heavy piece of basalt (large cobble or small boulder) or sandstone (typically a tabular slab) on/around the head, torso, and/or pelvis. Several of the crania are warped in a manner that suggests that the resulting pressure was imposed while the bodies were fresh. Over time, bodies were compacted by the overburden of additional interments, and their stone markers as the central platform grew into a mound; some skeletons were compressed to $<5 \mathrm{~cm}$ in vertical space. The overburden may also have caused repositioning of some bodies. Among the densely clustered burials of Lothagam North, there are no patterns of differentiation by age, sex, or material wealth as reflected by the presence of personal adornment. One possible example of a dedicated area within the mortuary cavity was the close proximity of three infants and one young child (GeJi9 Burials 5, 7, 8, and 10) found at different depths but all within the southern extent of the $2 \times 2 \mathrm{~m}^{2}$ trench.

One stone circle was excavated at Lothagam North. It held a bundle burial representing at least two adults and one older juvenile. Bone preservation of these elements was significantly better than was seen in the central 
Fig. 5 Plan (top) and southern profile (bottom)

orthophotographs of unit n04e42 with burial extents (coloured and numbered polygons) and stone beads (red marks). Burial extents are drawn around all point provenience data associated with each skeleton. Stone bead locations were recorded in the field via total station. Note the profile view excludes burials 18 and 19 as these burials are located in a pit along the north wall that is not visible in the southern profile

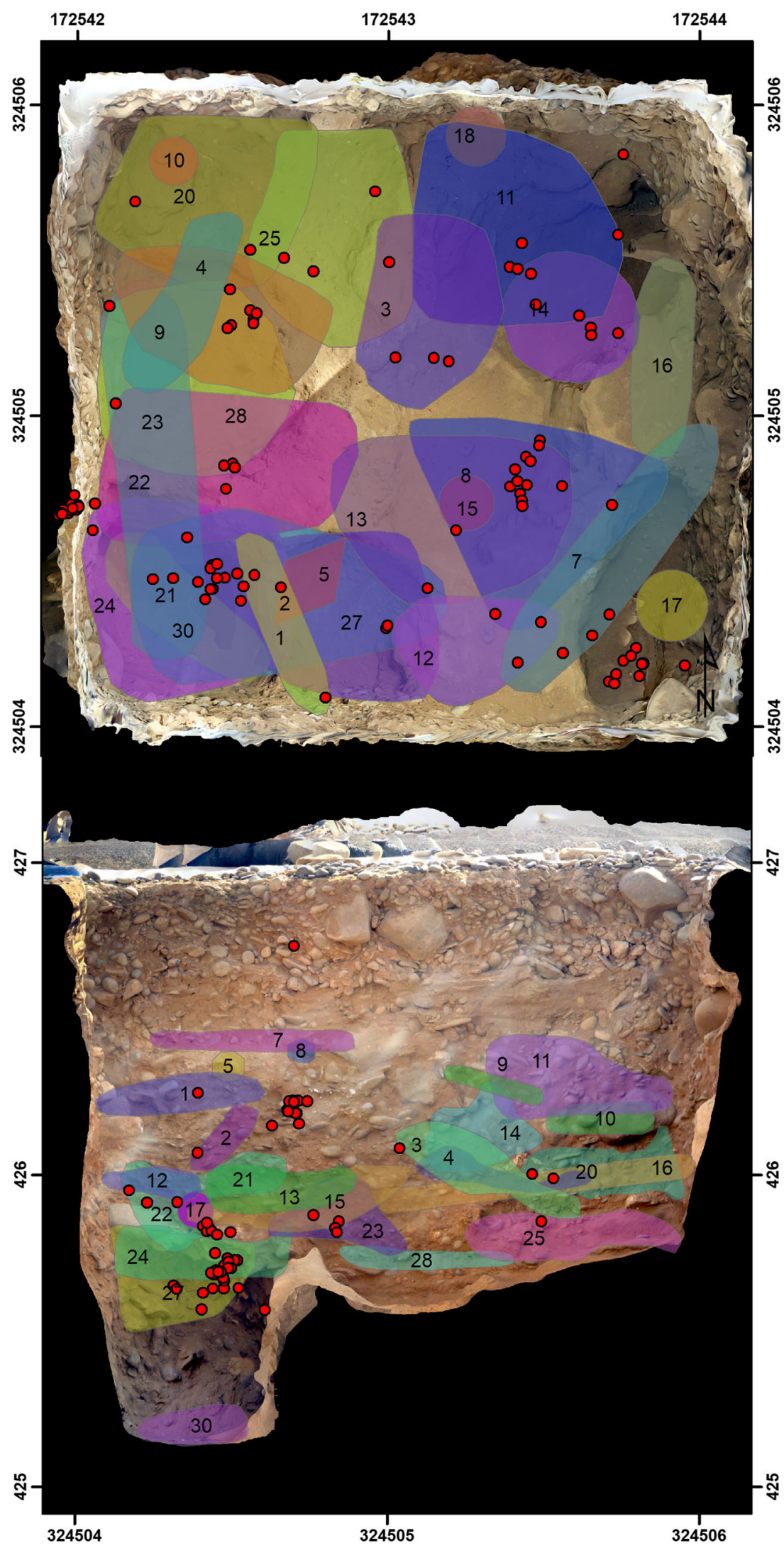

within this feature falls within the range of dates from

the central platform (Hildebrand et al. 2018), suggesting platform, perhaps because of the shallower depth and lack of rocky overburden. A radiocarbon date on charcoal 
either contemporaneity of use or later recycling of platform fill to a new context.

\section{Other pillar sites}

Excavations at Lothagam West and Manemanya were less extensive, but it is clear that these platforms also contain multiple burials. Two partial individuals were recovered from pits within the central platform at Lothagam West, with additional pit features visible in profile. At Manemanya, the lower $1 \times$ $2 \mathrm{~m}^{2}$ step of excavations into the platform encountered the feet of an arthritic adult jutting perpendicularly over a burial of a young adult woman. Their positioning suggests the presence of diversely oriented burials, similar to Lothagam North. Platform deposits at both sites were shallower than at Lothagam North, and we encountered sterile substrates beneath the lowest burials. At Kalokol, no human remains were encountered during 2009 excavations into the platform, although our units were placed along the southeast periphery which may have been outside the extent of burial deposits (see Fig. 4).

Cairns at Lothagam West and Kalokol contained burials, but these interments may post-date creation of the central platforms at their respective sites. At Lothagam West, a $\sim 5$-yearold child was recovered from the centre of a cairn just east of the central platform on the opposite side of the line of pillars. Excavation of the cairn's margins revealed it to have been dug into platform deposits. At Kalokol, excavations of one cairn in 2012 revealed a central pit containing probable human remains which were not excavated; this feature also intruded into pre-existing platform deposits. In 2017, local collaborators reported looting of a different cairn located just west of the site, approximately $20 \mathrm{~m}$ away from the platform outside the curb. Fragmentary human remains were salvaged, but the degree of sun-bleaching and weathering indicated they had been exposed for some time. The poorly preserved bones belong to at least one adult; age and sex could not be determined. The antiquity of the cairns at Kalokol and their association with the platform and pillars remain unclear.

\section{Cultural materials from the burials}

\section{Lothagam North}

Ornaments, primarily stone and OES beads, were the most common artefacts found in direct association with burials. We recovered 302 stone beads/pendants from deposits at Lothagam North, of which 173 were directly associated with 20 of the 31 excavated burial features (Table 2, Fig. 5). Other burials likely also contained beads, but the proximity of bodies and rocky matrix made it difficult to associate items with specific skeletons. Stone beads span a range of raw materials, colours, and forms (Hildebrand et al. 2018). Mineral and rock groups include (in descending order of frequency) zeolite (analcime), amazonite, talc schist (soapstone), chalcedony, volcanic rock (typically andesite, phonolite, or basalt host rock), fluorite, and limestone. Individual beads made from calcite, gypsum, chlorite (schist), haematite, and an iron precipitate were also noted. Analcime (45\%) and amazonite $(32 \%)$ dominate the assemblage, making for a primarily pink-and-blue colouring. Colours range from orange/red (chalcedonies), deep to light purple (fluorites), dark green (talc), off-white (limestone), and shades of black (volcanics); a brilliant white scolecite (zeolite) bead and a haematitecemented sandstone pendent add lustre to the collection. Many of these stones and minerals are also represented in the collections from Jarigole, including amazonite (Nelson 1995).

Most were shaped into round beads of varying sizes; other forms included pendants, and incomplete circles that may have been designed as earrings. Jewellery observed in situ includes single ornaments (e.g. an amazonite 'earring' with GeJi9 B-29), groupings manufactured from a single type of mineral (e.g. a necklace made of amazonite beads and pendants with GeJi9 B-19), and groupings that included various combinations of raw materials, colours, and forms (e.g. amazonite, basalt, analcime and stromatolite stone beads and organic beads with GeJi9 B-12) (Fig. 6). Mineralogical surveys of the region suggest that many of the raw materials, such as the zeolite and chalcedony, could have been sourced close to Lothagam North. Other materials such as the fluorite and amazonite could have come from the Rift Valley, but from more distant and more distinct (i.e. unitary) sources. Bone beads made from fragile, small faunal diaphyses were also found (GeJi9 B-12, see Fig. 6). OES beads were ubiquitous throughout the central platform deposits. Bead counts from a representative subset of four units (of the excavated ten) yielded 522 whole and 37 partial OES beads, suggesting a total of 1250-1500 OES beads for the Lothagam North excavated units.

Other grave goods from Lothagam North include faunal elements; some apparently incorporated into garments. Around the occipital portion of the skull of GeJi9 B-3, 405 gerbil (Gerbiliscus sp.) incisors representing at least 113 animals were configured in a bricklike lattice pattern, suggesting they had been fixed to a headpiece or wrap whose supporting material did not preserve. GeJi9 B-4's torso was found with 49 hyrax (cf. Heterohyrax sp.) upper incisors from at least 25 animals. Ivory ornaments and bangles were found with several of the burials. GeJi9 B-26A was buried next to 12 perforated hippo (Hippopotamus amphibious) tusks that may have been strung together and worn. This feature overlaid a bundle burial containing three skulls facing into the ground as well as commingled post-cranial bones (GeJi9 B-26B/C/D). East of the platform, an unmodified Nile softshell turtle (Trionyx triunguis) vertebra was found within the stone circle bundle burial (GeJi9 B-6). These 
Table 1 Mortuary context for burials excavated from GeJi9, GeJi10, and GcJh5 (Ad, adult, Juv, juvenile, $M$, male, $F$, female, $M$ ?, probable male, $F$ ?, probable female,?, sex undetermined)

\begin{tabular}{|c|c|c|c|c|c|c|c|c|}
\hline Burial & MNI & $\begin{array}{l}\text { Burial } \\
\text { Type }\end{array}$ & Age/Sex & Position & Side & $\begin{array}{l}\text { Orientation } \\
\text { (head) }\end{array}$ & Facing & Burial context \\
\hline \multicolumn{9}{|c|}{ LOTHAGAM NORTH (GeJi9) } \\
\hline 1 & 1 & Primary & $\mathrm{Ad} / \mathrm{M}$ & Prone, flexed & & $\mathrm{N}-\underline{\mathrm{S}}$ & $\mathrm{E}$ & $\begin{array}{l}\text { Boulder on torso, arms and legs flexed beneath body, one } \\
\text { hand by face }\end{array}$ \\
\hline 2 & 1 & Primary & $\mathrm{Ad} / \mathrm{M}$ & Prone, flexed & $\mathrm{R}$ & $\underline{N}-\mathrm{S} / \mathrm{SW}$ & $\mathrm{W}$ & Directly below B-1, left arm/leg partly extended (slumped) \\
\hline 3 & 1 & Primary & $\mathrm{Ad} / \mathrm{M} ?$ & Flexed & $\mathrm{L}$ & $\mathrm{E}-\underline{\mathrm{W}}$ & $\mathrm{N}-\mathrm{NE}$ & Tightly flexed/crouched, slumped onto left side \\
\hline 4 & 1 & Primary & $\mathrm{Ad} / ?$ & Flexed & $?$ & $\mathrm{~N}-\underline{\mathrm{S}}$ & $\mathrm{E}$ & \\
\hline 5 & 1 & Primary & Infant & & & & & Poorly preserved neonate \\
\hline 6 & 3 & Secondary & $\begin{array}{l}\mathrm{Ad} / \mathrm{M} \\
\mathrm{Ad} / ? \\
\text { Juv }\end{array}$ & Bundle & & $\mathrm{N}-\mathrm{S}$ & & $\begin{array}{l}\text { Bundle with parts of } 3 \text { disarticulated individuals, in pit in } \\
\text { centre of stone circle }\end{array}$ \\
\hline 7 & 1 & Primary & Infant & Flexed & $\mathrm{R}$ & NE-SW & SE & \\
\hline 8 & 1 & Primary & Infant & Supine & & $\underline{N}-\mathrm{S}$ & Up & Neonate, right arm beneath torso \\
\hline 9 & 1 & Primary & $\mathrm{Ad} / \mathrm{F}$ & Flexed & $\mathrm{R}$ & $\underline{E}-W$ & $\mathrm{~N} / \mathrm{NW}$ & $\begin{array}{l}\text { Left arm flexed around head, face in elbow. Ring of rocks } \\
\text { around head, slab on torso }\end{array}$ \\
\hline 10 & 1 & Primary & Juv & Flexed & $\mathrm{L}$ & $\underline{N}-\mathrm{S}$ & $\mathrm{E}$ & Slab on torso \\
\hline 11 & 1 & Primary & $\mathrm{Ad} / \mathrm{F}$ & Flexed & $\mathrm{R}$ & NE-SW & $\mathrm{N} / \mathrm{NW}$ & Slab on head and body, left arm flexed but shoulder high \\
\hline 12 & 1 & Primary & $\mathrm{Ad} / \mathrm{M}$ & Flexed & $\mathrm{R}$ & $\underline{E}-W$ & $\mathrm{~N}$ & $\begin{array}{l}\text { Slab over pelvis, left arm by chest, right arm semi-flexed } \\
\text { under knees }\end{array}$ \\
\hline 13 & 1 & Secondary & $\mathrm{Ad} / \mathrm{M} ?$ & Bundle & & SE-NW & & \\
\hline 14 & 1 & Primary & $\mathrm{Ad} / \mathrm{F} ?$ & Prone & & $\underline{E}-W$ & W/NW & Slab over torso, right arm and lower body absent \\
\hline 15 & 3 & Primary & $\begin{array}{l}2 \mathrm{Ad} / \mathrm{F} ? \\
\mathrm{Ad} / ?\end{array}$ & Flexed & $\mathrm{R} / \mathrm{R} / ?$ & $\underline{\mathrm{N}}-\mathrm{S} / \underline{\mathrm{N}}-\mathrm{S} / \underline{\mathrm{E}}-\mathrm{W} ?$ & $W / \mathrm{W} / \mathrm{S} ?$ & $\begin{array}{l}\text { Double burial with two flexed adults, third poorly preserved } \\
\text { individual near feet }\end{array}$ \\
\hline 16 & 2 & $\begin{array}{l}\text { Primary, } \\
\text { Secon- } \\
\text { dary }\end{array}$ & $2 \mathrm{Ad} / ?$ & & & $\begin{array}{l}\text { SE-NW } \\
\text { (bundle) }\end{array}$ & & $\begin{array}{l}\text { Commingled remains of several poorly preserved } \\
\text { individuals, at least } 1 \text { flexed primary and } 1 \text { bundle burial }\end{array}$ \\
\hline 17 & 1 & Primary & $\mathrm{Ad} / \mathrm{M} ?$ & Flexed & $\mathrm{R}$ & NE-SW & NW? & Poorly preserved burial on top of pit \\
\hline 18 & 2 & Primary & $2 \mathrm{Ad} / \mathrm{M}$ & Flexed & $\mathrm{R} / \mathrm{R}$ & $\underline{\mathrm{E}}-\mathrm{W} / \underline{\mathrm{NE}}-\mathrm{SW}$ & $\mathrm{N} / \mathrm{N}$ & Double burial inside bedrock pit, one on top of the other \\
\hline 19 & 1 & Primary & $\mathrm{Juv} / \mathrm{F} ?$ & & $\mathrm{~L}$ & $\underline{E}-W$ & $\mathrm{~S}$ & Poorly preserved burial of $\sim 16$ year old in bedrock pit \\
\hline 20 & 1 & Primary & $\mathrm{Ad} / \mathrm{F} ?$ & Flexed & $\mathrm{R}$ & $\underline{E}-W$ & $\mathrm{~W}$ & Boulder on head, tightly flexed \\
\hline 21 & 2 & Primary & $\begin{array}{l}\mathrm{Ad} / \mathrm{M} ? \\
\mathrm{Ad} / \mathrm{F} ?\end{array}$ & Prone/Flexed & $\mathrm{R}$ & $\underline{E}-W$ & & $\begin{array}{l}\text { Flexed, slumped onto stomach. Found with additional } \\
\text { isolated right os coxa }\end{array}$ \\
\hline 22 & 2 & Primary? & $\mathrm{Ad} / \mathrm{M} ? \mathrm{Ad} / ?$ & & & N-S-NW-SE & & $\begin{array}{l}\text { Poorly preserved and commingled remains of at least two } \\
\text { individuals }\end{array}$ \\
\hline 23 & 1 & Primary & $\mathrm{Ad} / \mathrm{F}$ & Flexed & $\mathrm{R}$ & $\underline{E}-W$ & NW & Lying on bedrock, slabs on head and torso \\
\hline 24 & 3 & Primary & $\begin{array}{l}\mathrm{Ad} / \mathrm{F}, \mathrm{Ad} / ?, \\
\quad \text { Infant }\end{array}$ & Flexed & $\mathrm{R}$ & $\underline{\text { NE-SW }}$ & W & $\begin{array}{l}\text { Primary burial in bedrock pit with parts of second adult and } \\
\text { child. Head resting on edge of pit, body curled around } \\
\text { possible grindstone }\end{array}$ \\
\hline 25 & 1 & Primary & $\mathrm{Ad} / \mathrm{M}$ & Flexed & $\mathrm{L}$ & $\underline{\mathrm{N}}-\mathrm{S}$ & $\mathrm{E}$ & $\begin{array}{l}\text { In bedrock pit, slabs on head, shoulders, forearms, and } \\
\text { knees }\end{array}$ \\
\hline 26 & 4 & $\begin{array}{l}\text { Primary, } \\
\text { Secon- } \\
\text { dary }\end{array}$ & $\begin{array}{l}\mathrm{Ad} / \mathrm{M} \\
2 \mathrm{Ad} / \mathrm{M} ? \\
\mathrm{Ad} / ?\end{array}$ & $\begin{array}{l}\text { Flexed, } \\
\text { Bundle }\end{array}$ & $\mathrm{R} /-$ & E-W/E-W & $\mathrm{N} /$ down & $\begin{array}{l}\text { Primary burial with slab on torso, head between two } \\
\text { boulders, overlying bundle burial with three } \\
\text { disarticulated skulls under boulders and commingled } \\
\text { postcrania }\end{array}$ \\
\hline 27 & 1 & Primary & $\mathrm{Ad} / ?$ & Flexed & $\mathrm{L}$ & $\underline{\text { NE-SW }}$ & $\mathrm{S} /$ down & In bedrock pit \\
\hline 28 & 1 & Secondary & $\mathrm{Ad} / \mathrm{F}$ & Supine & & $\underline{\mathrm{S}}-\mathrm{N}$ & & Secondary burial of an isolated pelvis \\
\hline 29 & 1 & Primary & $\mathrm{Ad} / \mathrm{M} ?$ & Flexed & $\mathrm{R}$ & $\underline{\mathrm{E}}-\mathrm{W}$ & N/down & In bedrock pit, slab on head and torso \\
\hline 30 & 1 & Primary & $\mathrm{Ad} / \mathrm{M} ?$ & Flexed & $\mathrm{R}$ & NW-SE & NE & In bedrock pit \\
\hline A0 & 1 & Primary & Infant & & & & & Head beneath two slabs \\
\hline \multicolumn{9}{|c|}{ LOTHAGAM WEST (GeJi1)0 } \\
\hline 1 & 1 & $?$ & Juv? & & & & & Ribs displaced from an unexcavated pit \\
\hline 2 & 1 & Primary & Juv & & $\mathrm{R}$ & $\underline{\mathrm{N}}-\mathrm{S}$ & W & Child in centre of cairn, skull beneath two large boulders \\
\hline
\end{tabular}


Table 1 (continued)

\begin{tabular}{|c|c|c|c|c|c|c|c|c|}
\hline Burial & MNI & $\begin{array}{l}\text { Burial } \\
\text { Type }\end{array}$ & Age/Sex & Position & Side & $\begin{array}{l}\text { Orientation } \\
\text { (head) }\end{array}$ & Facing & Burial context \\
\hline 3 & 1 & Primary & $\mathrm{Ad} / \mathrm{M}$ & Flexed & $\mathrm{L}$ & $\underline{N}-\mathrm{S}$ & $\mathrm{E}$ & $\begin{array}{l}\text { In bedrock pit, body on steep incline with head low and feet } \\
\text { high, covered in cobbles }\end{array}$ \\
\hline \multicolumn{9}{|c|}{ MANEMANYA GcJh5 } \\
\hline 1 & 1 & Primary & $\mathrm{Ad} / \mathrm{F}$ & Partly flexed & $\mathrm{R}$ & $\mathrm{N}-\underline{\mathrm{S}}$ & NW & $\begin{array}{l}\text { Upper body supine, arms extended, legs tightly flexed. } \\
\text { Large boulder on skull, body covered with smaller } \\
\text { cobbles. Charcoal/ash beneath the body }\end{array}$ \\
\hline 2 & 1 & Primary? & $\mathrm{Ad} / ?$ & & & & & $\begin{array}{l}\text { Articulated feet extending over the torso of Manemanya } \\
\text { Burial 1, rest of burial unexcavated }\end{array}$ \\
\hline
\end{tabular}

examples stand apart from other faunal remains recovered from burial fill, which were highly fragmentary and generally could only be identified to mammal, bird, or fish categories.

\section{Other sites}

Only one complete burial was excavated from Manemanya, but the feature included extensive cultural material (Fig. 7). The torso of a probable woman in her late 20 s to early 30 s (GcJh5 B-1) was covered by 329 stone beads of somewhat diverse shapes and sizes, further accompanied by at least 9559 whole and 978 broken OES beads. Beads were densely concentrated on and immediately around her body, suggesting they were contained with the body within a wrap or shroud. She was buried on her back with her arms at her sides and legs tightly flexed to the right. The body appeared to have been lain on a relatively flat, undisturbed surface. There was charcoal beneath the body. She wore a necklace that included five gourd-shaped stone beads. Hundreds of larger, round stone beads encircled her torso and pelvis in linear arrangements, suggesting they were part of a garment. Twenty-six exceptionally small OES beads clustered bilaterally near her ears, probably worn as elaborate earrings, while staggered dyads of slightly larger OES beads likely decorated a garment or placket extending down her legs. Numerous strands of OES beads were draped over her rib cage, spine, and pelvis but did not extend beneath her torso, nor did they go around her neck. In addition to beads, she wore perforated carnivore teeth as ornaments - pendants on her upper torso made from lion (Panthera leo) and hyena (Hyaena hyaena) teeth, and a bracelet of 42 canid (Canis sp.) teeth around her left wrist (Fig. 7). An ivory bangle encircled her right wrist. An unidentified, badly degraded composite object made of worked bone and ivory was found near her right shoulder. The perforation of the bone component suggests it was worn or hung, and the size of its bone and ivory components are consistent with a very large animal, possibly hippo.
As noted, we encountered a pair of feet from a second individual above GcJh5 B-1's torso and observed human bone in the walls of the $1 \times 2 \mathrm{~m}^{2}$ lower trench, indicating other burials are present in deeper reaches of the platform. Further excavation would be needed to determine if the degree of ornamentation seen with the young woman was typical, or if this individual represents an unusual case.

The stone beads at Manemanya are similar to one another in size and shape (as seen in Fig. 7). They were fashioned from raw materials different from those used at Lothagam North. They are almost exclusively calcite, with one bead made from sandstone. With colour variations only slight (off-white to soft pink), the Manemanya beads lack the dramatic hues of the Lothagam North assemblage, but their larger dimensions would still have strong visual impact. Their materials would have been readily available and are easier to work than some of the harder materials (e.g. chalcedonies) found at Lothagam North. The seemingly simpler material technology of the GcJh5 B-1 assemblage, however, is contrasted by the number of accompanying beads. This one burial yielded a stone bead count equivalent to 30 burials at Lothagam North, and more than five times the estimated number of ostrich eggshell beads from Lothagam North's larger mortuary excavation area.

The other two excavated pillar sites, Kalokol and Lothagam West, yielded fewer burials and, unsurprisingly, almost no burial goods. Only $\sim 10$ OES beads total were recovered from Lothagam West, most of which were in association with the most complete burial GeJi10 B-3. No beads were recovered from Kalokol.

\section{The human remains}

Skeletons excavated from Lothagam North, Lothagam West, and Manemanya represent both males and females, and range in age from neonates to the elderly (Table 3, $n=49$ ). Of the 39 adults and one older adolescent in this sample, 18 are probable males and 12 are probable females. Ten individuals are too poorly preserved or incomplete to estimate sex. Of the individuals whose ages at death could be estimated, eight are 
Table 2 Ornamentation and other inclusions for burials excavated from GeJi9, GeJi10, and GcJh5

Burial Stone bead Stone bead materials

Ornament description

Other inclusions

(n)

\begin{tabular}{lrl}
\multicolumn{2}{l}{ Lothagam } \\
1 & 1 & \multicolumn{2}{l}{ North GeJi9 } \\
2 & 5 & $\begin{array}{l}\text { Volcanic (basalt) } \\
\text { Amazonite }\end{array}$ \\
3 & 5 & Talc, chalcedony (carnelian), scolecite \\
& & \\
4 & 24 & Amazonite, analcime, limestone (stromatolite) \\
5 & & \\
6 & & \\
7 & 2 & Amazonite \\
8 & 1 & Amazonite \\
9 & 5 & Amazonite, talc \\
10 & 1 & Amazonite, volcanic (basalt), fluorite \\
11 & 8 & Amazonite, volcanic (basalt), analcime, limestone \\
12 & 12 & (stromatolite)
\end{tabular}

$\begin{array}{rrl}13 & & \\ 14 & 1 & \text { Limestone (stromatolite) } \\ 15 & 19 & \text { Analcime }\end{array}$

16

$\begin{array}{rrl}23 & 1 & \begin{array}{l}\text { Analcime } \\ \text { Amazonite, analcime, ivory }\end{array} \\ 24 & 2 & \text { Talc } \\ 25 & 1 & \text { Amazonite, analcime, ivory }\end{array}$

$27 \quad$ Fluorite, volcanic (basalt)

None recovered

Stone bead at neck

Stone earring at left temporal, stone beads at neck

Gerbil-tooth headpiece, stone earring, stone beads near knees, ivory bangles on left arm

Stone beads and earring, hyrax teeth lying on chest

OES beads at wrist

Stone beads at neck, OES at pelvis

Turtle vertebra

Stone bead at right arm

Stone bead necklace

Stone and OES beads at neck, OES at pelvis

Stone and OES beads at neck

Stone beads at neck, stone earring near forearm, ivory at chest, bone beads at hip and left ankle

Beads and earring at neck, ivory squares at chest Stone beads around two individuals' necks, ivory bangle around one wrist

Bone and OES beads, ivory squares, and possible tusk

None recovered

None recovered

Stone bead necklace

Stone and OES beads within burial fill

OES beads within burial fill

Four ivory rings on one left hand, beads by right hand

Stone bead necklace

Stone bead necklace, OES beads near pelvis, stone and OES beads within burial fill

Stone bead near mandible

Twelve perforated hippo tusks, stone and bone bead necklace with primary burial; stone bead necklace, earring, loose stone beads, and ivory ring within bundle burial

Stone beads and ivory within burial fill, OES beads near left shoulder

None recovered

Stone bead within burial fill

Zoomorphic stone palette (between 26 and 29)

Ochre staining on skull

Ochre-stained rock

Ochre staining on skull

Ochre staining on arms, torso, cranium

Possible grindstone

Zoomorphic stone palette (between 26 and 29)

OES beads within burial fill

OES beads within burial fill

Abundant stone and OES beads covering body, perforated carnivore teeth pendants and bracelet, ivory bangles

Ivory and modified bone object found near body 
young adults $(\sim 18-30$ years $), 10$ are middle-aged $(\sim 30-$ 50 years), and five appear to be elderly (50+). Sixteen could only be assessed as adult. Five infants (newborn to 2 years) and five juveniles ( 2 to 18 years) were also recovered. The scarcity of complete long bones limited estimations of stature, mass, and proportionality. Based on a small sample of adults, males' stature averaged around $169 \mathrm{~cm}(n=9)$ and females were around $163 \mathrm{~cm}(n=3)$ (methods per Meadows and Jantz 1992; Trotter 1970; Trotter and Gleser 1952). Average body mass estimated from femur head size is approximately $62 \mathrm{~kg}(n=3$, all probable males) (McHenry 1992; Ruff et al. 1991). Coefficients of variation (CV) for metric variables with a sample size of $\geq 10$ are relatively low (mean $=13.28 \%, n=$ 20 variables) suggesting that the people buried at these sites may constitute a deme - a subgroup of closely related individuals (Table 4).

\section{Indicators of health}

We noted no indications of endemic disease or violent causes of death. The most commonly observed pathological features are osteoarthritis, dental hypoplasias, and healed fractures. Osteoarthritis (OA) and degenerative joint disease (DJD), characterized by articular cartilage destruction and associated bony porosity and lipping at joints, are relatively common among the adults. Twenty of the 39 adults have preserved joint surfaces that could be scored for OA, of which 14 skeletons (70\%) show some combination of osteophytes, lipping, and/or eburnation. These were typically observed in the spine, shoulders, knees, and feet, although differential preservation of skeletons prevents systematic scoring of all joint surfaces. $\mathrm{OA}$ is found more commonly among the middle-aged adults (5 of 8 observed, $63 \%$ ) and older adults (3 of 4 observed, $75 \%$ ) compared to the young adults. Distribution is relatively equal between the sexes.

Among the dentitions, two of the 25 individuals possess caries ( $n=3$ of 331 teeth that could be assessed), and all cases are slight. Tooth wear is moderate: the average mandibular third molar wear score is $2.4(n=14)$, where cusps are moderately blunted with only pinpoint dentine exposure, if any (Smith 1984). Dental calculus is pervasive, particularly in older adults. Calculus is present on most teeth that could be scored $(66 \%, n=426$ teeth assessed). The only case of abscessing was observed in GeJi9 B-25 on the left maxilla around the left second premolar, with a fistula leading into the maxillary sinus. The partial dentition of this elderly man also has large calculus deposits. Periodontal disease and antemortem tooth loss are rare, although poor preservation of jaws and alveolar tissue made these processes difficult to study. By contrast, enamel hypoplasias are seen in $68 \%$ of individuals ( $n=13 / 19$ dentitions that could be scored). Defects include transverse lines (linear enamel hypoplasia, or LEH), grooves, and pits.

The crania of only five of 49 individuals could be assessed for cribra orbitalia and porotic hyperostosis. An adult woman (GeJi9 B-24A) presents the sole case, with cribriform lesions visible on the orbital roof paired with minor periosteal activity on the right supraorbital area. Another individual, an elderly male over 50 years old (GeJi10 B-3), has indications of low bone mass suggestive of osteoporosis.
Fig. 6 Examples of stone beads accompanying the burials within Lothagam North's central platform, including a GeJi9 B-12's assemblage of analcime, stromatolite, amazonite, carnelian, and talc (soapstone) beads, found in conjunction with a bone point; b GeJi9 B-19's assemblage of primarily amazonite beads and pendants as well as a broken analcime bead and a fragment of rodent tooth/ivory; and c a large amazonite 'earring' found with GeJi9 B-29. Image by Carla Klehm

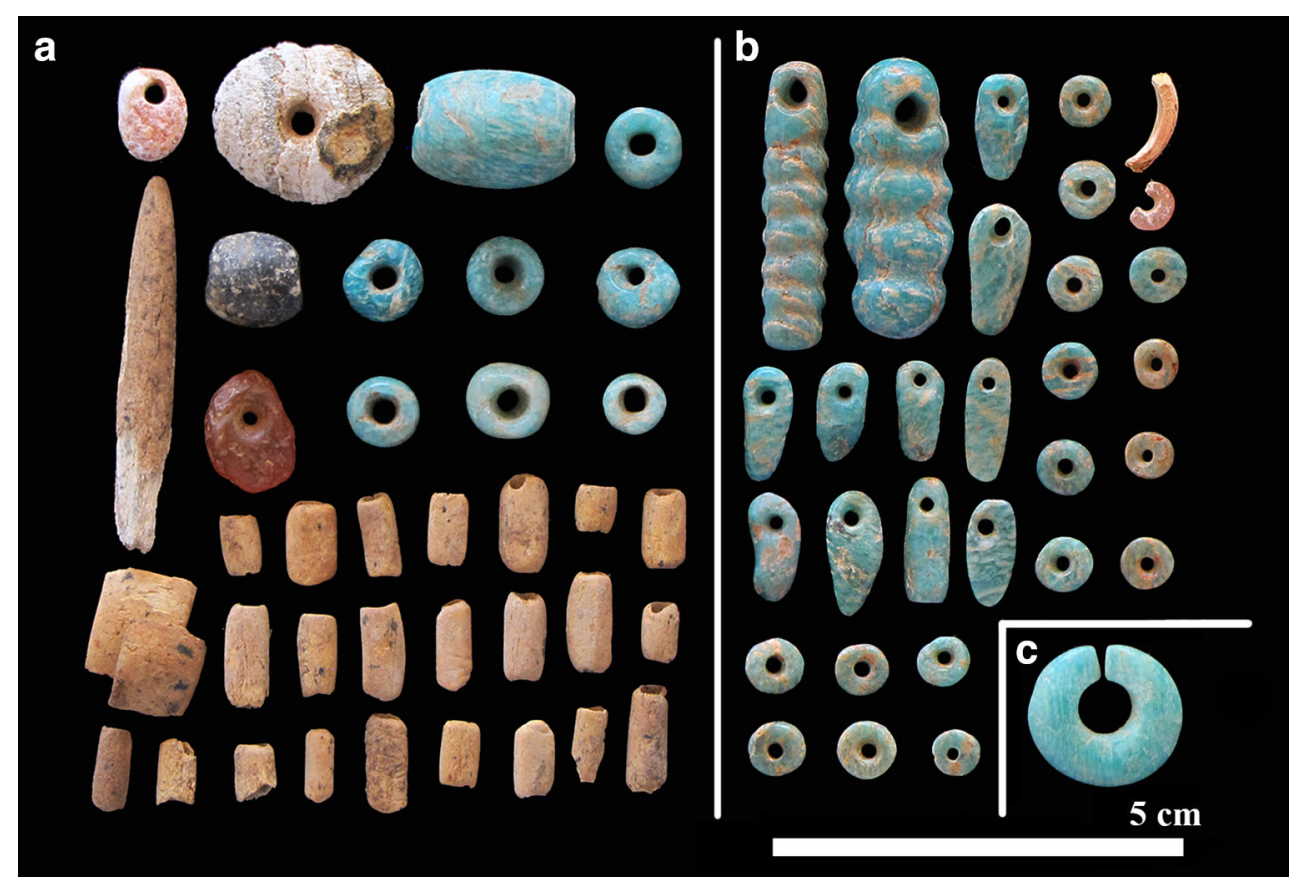


Fig. 7 Examples of stone, shell, and bone adornments found with GcJh5 B-1 at Manemanya. These include (A) ivory fragments, Hyaena hyaena pendant, and Canis sp. tooth bracelet beads; (B) an unidentified bone and ivory object; (C) large and small ostrich eggshell beads; (D) an ivory bracelet, pendant, and other fragments; and (E) numerous large calcite stone beads strung into necklaces, many of which were found still in situ and strung in order (as pictured here). Image by Carla Klehm

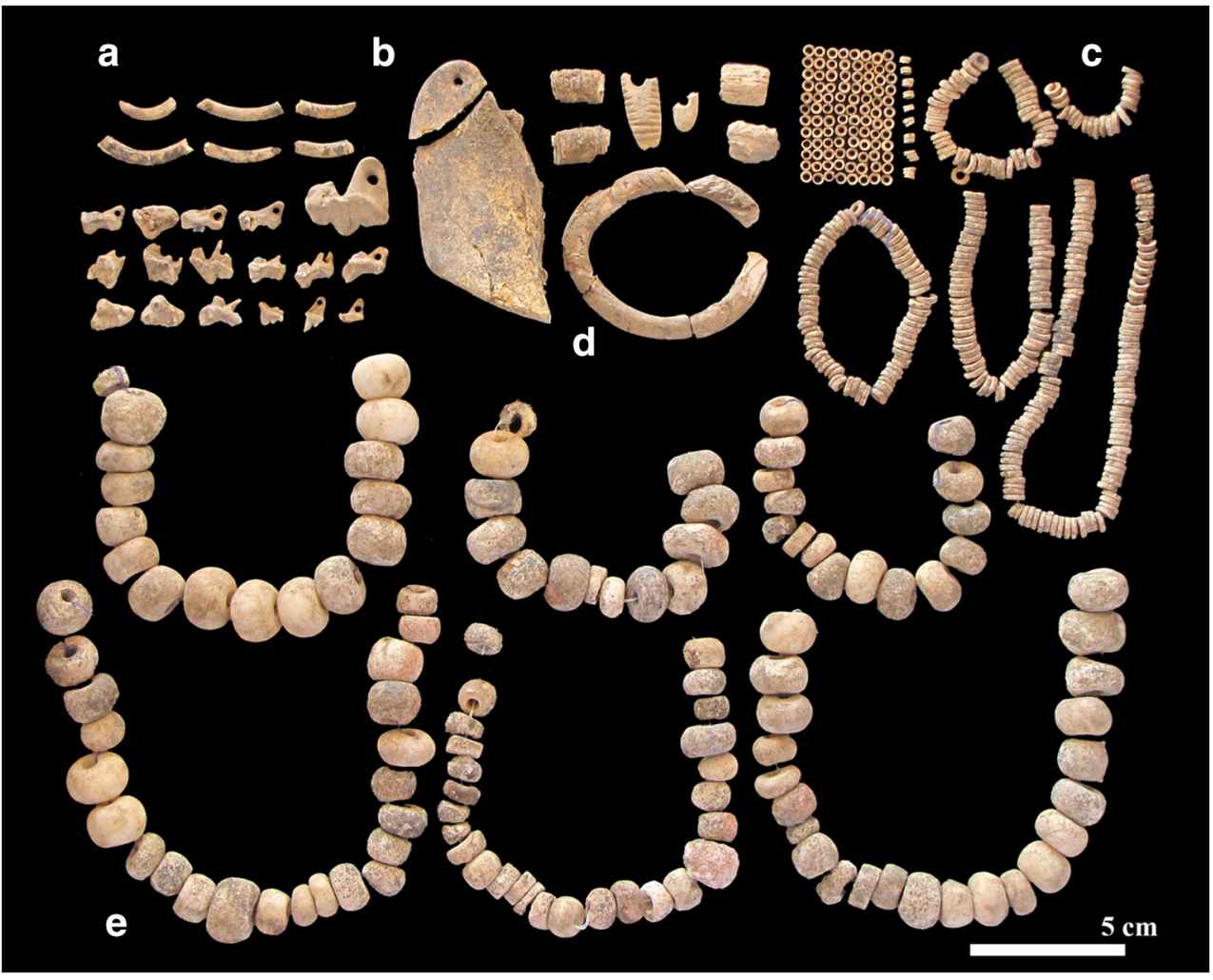

Cases of possible infectious disease include GeJi9 B-7, an infant aged 6 to 12 months whose frontal bone shows disorganized new bone endocranially, on the squamous portion. The endocranial bone is highly thickened and vascularized but the outer table appears normal, consistent with a nonspecific indicator of haemorrhage or infection (Lewis 2004). GeJi9 B-21A (male, 20-30 years) and GeJi9 B-28 (female, 30-40 years) both show non-taphonomic erosion around the pubic symphysis from either infection or pelvic stress injury. We also documented healed fractures on various fingers, toes, and ribs on three individuals (GeJi9 B-1, B-2, B-25). Healed fractures may also account for mild OA on two rib heads of GcJh5 B-1 and a discrepancy in femur lengths in GeJi9 B-6A.

The young woman from Manemanya buried with thousands of beads (GcJh5 B-1) shows several skeletal anomalies that suggest asymmetries to her face and jaw. Her left zygomatic bears a bony spur along the temporal margin where the temporal fascia attach. This feature, which is not present on the well-preserved right side, may be related to the pattern of greater wear on the right side of the dentition, greater dental calculus on the left side, and asymmetry in the mandibular rami. The right mandibular ramus is more prominently inverted at gonion, with asymmetries extending through the submandibular fossa region (inferior to the mylohyoid line). Other distinguishing features of her skull include four large wormian bones and a notably thin occipital squamous portion which, taken in concert, may suggest a congenital or developmental origin for the asymmetry. Facial asymmetry can arise from congenital, developmental, and acquired factors (Thiesen et al. 2015). One possibility in this case is congenital muscular torticollis (wry-neck). Limited ranges of motion and repose can lead to asymmetries of the face and head (Nilesh and Mukherji 2013). Given that she was also relatively tall ( $170-180 \mathrm{~cm}$, based on estimated maximum femur length, measured in situ), perhaps her appearance and bearing were in some ways linked to her burial treatment.

Table 3 Estimated age/sex of excavated individuals $(n=49)$

\begin{tabular}{|c|c|c|c|c|c|c|c|c|c|}
\hline Site & Probable M & Probable F & $\begin{array}{l}\text { Juvenile/ } \\
\text { undetermined }\end{array}$ & Birth-2 years & $\begin{array}{l}\text { Juvenile } \\
2-18\end{array}$ & $\begin{array}{l}\text { Young adult } \\
(18-30)\end{array}$ & $\begin{array}{l}\text { Middle adult } \\
(30-50)\end{array}$ & $\begin{array}{l}\text { Older adult } \\
(50+)\end{array}$ & $\begin{array}{l}\text { Adult } \\
(18- \\
50+)\end{array}$ \\
\hline GeJi9 & 17 & 11 & 16 & 5 & 3 & 7 & 10 & 4 & 15 \\
\hline GeJi10 & 1 & 0 & 2 & 0 & 2 & 0 & 0 & 1 & 0 \\
\hline GcJh5 & 0 & 1 & 1 & 0 & 0 & 1 & 0 & 0 & 1 \\
\hline
\end{tabular}


Table 4 Statistical summary of measurements (all in $\mathrm{mm}$ ) for which $\geq 10$ adults could be assessed

\begin{tabular}{|c|c|c|c|c|c|}
\hline Bone & Variable & Adults $(n)$ & Mean & S.D. & C.V. \\
\hline \multirow[t]{2}{*}{ Mandible } & Condyle (ant-pos) & 12 & 9.27 & 1.16 & 12.56 \\
\hline & Condyle (med-lat) & 12 & 19.86 & 2.47 & 12.46 \\
\hline \multirow[t]{3}{*}{ Clavicle } & Midshaft (ant-pos) & 14 & 11.30 & 1.47 & 13.03 \\
\hline & Midshaft (sup-inf) & 14 & 9.91 & 1.58 & 15.89 \\
\hline & Circumference & 11 & 38.32 & 3.14 & 8.20 \\
\hline \multirow[t]{2}{*}{ Humerus } & Midshaft (max) & 11 & 19.87 & 1.94 & 9.76 \\
\hline & Midshaft (min) & 11 & 17.38 & 2.49 & 14.33 \\
\hline \multirow[t]{3}{*}{ Capitate } & Length & 11 & 20.87 & 2.96 & 14.18 \\
\hline & Width & 10 & 19.20 & 2.81 & 14.61 \\
\hline & Depth & 10 & 13.41 & 3.28 & 24.47 \\
\hline \multirow[t]{3}{*}{ Hamate } & Length & 10 & 20.86 & 2.06 & 9.89 \\
\hline & Width & 11 & 18.08 & 2.91 & 16.08 \\
\hline & Depth & 11 & 16.60 & 5.49 & 33.06 \\
\hline \multirow[t]{2}{*}{ Lunate } & Length & 10 & 16.29 & 1.82 & 11.19 \\
\hline & Width & 10 & 14.89 & 1.83 & 12.28 \\
\hline \multirow[t]{3}{*}{ 3rd metacarpal } & Midshaft (med-lat) & 10 & 8.60 & 0.70 & 8.20 \\
\hline & Midshaft (dors-palm) & 10 & 7.91 & 0.66 & 8.37 \\
\hline & Base (dors-palm) & 10 & 14.58 & 1.53 & 10.48 \\
\hline \multirow[t]{2}{*}{ Patella } & Length & 10 & 37.74 & 3.04 & 8.05 \\
\hline & Depth & 12 & 19.22 & 1.64 & 8.51 \\
\hline Average & & & & & 13.28 \\
\hline
\end{tabular}

\section{Biomechanical indicators of mobility}

Biomechanical measures obtained from the 34 eligible midshaft elements are presented in Table 5. Table 6 contains mean values for elements analysed as well as summary data for the southern African comparative groups. For all skeletal elements, $I_{\max } / I_{\min }$ values fall within the range of variation of the southern African herding and foraging groups (examples in Fig. 8). There are no significant differences in $I_{\max } / I_{\min }$ for any of the upper limb elements. The $I_{\max } / I_{\min }$ values for the pillar site tibia and femora recovered are comparatively high relative to the southern African groups; however, tibia CSG property data are very limited. For the femora, there are significant differences between the four groups considered $(p=$ 0.00 ). However, there are no pairwise significant differences, likely due to the small sample sizes.

\section{Discussion}

Bioarchaeological insights from the western pillar sites offer fresh perspectives on the construction and use of pillar sites, as well as novel insights into the lived experienced of those
Table 5 Cross-sectional geometric (CSG) properties for pillar site individuals

\begin{tabular}{|c|c|c|c|}
\hline Skeleton & Est. Sex & Side & $\begin{array}{l}\mathrm{I}_{\max } / \\
\mathrm{I}_{\min }\end{array}$ \\
\hline \multicolumn{4}{|l|}{ HUMERUS } \\
\hline GcJh5 B-1 & $\mathrm{F}$ & $\mathrm{L}$ & 1.16 \\
\hline GcJh5 B-1 & $\mathrm{F}$ & $\mathrm{R}$ & 1.49 \\
\hline GeJi9 B-6A & M & $\mathrm{R}$ & 1.55 \\
\hline GeJi9 B-6B & $?$ & - & 1.53 \\
\hline GeJi9 B-3 & $\mathrm{M} ?$ & $\mathrm{~L}$ & 2.23 \\
\hline GeJi9 B-3 & $\mathrm{M} ?$ & $\mathrm{R}$ & 1.77 \\
\hline GeJi9 B-9 & $\mathrm{F}$ & $\mathrm{L}$ & 1.78 \\
\hline GeJi9 B-11 & $\mathrm{F}$ & $\mathrm{L}$ & 1.45 \\
\hline GeJi9 B-18B & M & $\mathrm{R}$ & 2.02 \\
\hline GeJi9 B-20 & $\mathrm{F}$ ? & $\mathrm{R}$ & 1.39 \\
\hline \multicolumn{4}{|l|}{ FEMUR } \\
\hline GcJh5 B-1 & $\mathrm{F}$ & $\mathrm{R}$ & 1.44 \\
\hline GeJi9 B-6A" & M & $\mathrm{L}$ & 2.21 \\
\hline GeJi9 B-6A" & M & $\mathrm{R}$ & 1.75 \\
\hline GeJi9 B-9 & $\mathrm{F}$ & $\mathrm{R}$ & 1.39 \\
\hline GeJi9 B-11 & $\mathrm{F}$ & $\mathrm{R}$ & 1.72 \\
\hline GeJI9 B-12 & M & $\mathrm{R}$ & 1.03 \\
\hline GeJi10 B-3 & M & $\mathrm{R}$ & 2.47 \\
\hline GbJj1 B-1 & M & $\mathrm{R}$ & 1.81 \\
\hline \multicolumn{4}{|l|}{ TIBIA } \\
\hline GeJi9 B-6A & M & $\mathrm{R}$ & 2.61 \\
\hline \multicolumn{4}{|l|}{ CLAVICLE } \\
\hline GeJi9 B-3 & M? & $\mathrm{L}$ & 1.49 \\
\hline GeJi9 B-3 & M? & $\mathrm{R}$ & 1.39 \\
\hline GeJi9 B-9 & $\mathrm{F}$ & $\mathrm{L}$ & 1.54 \\
\hline GeJi9 B15A & $\mathrm{F}$ ? & $\mathrm{R}$ & 2.11 \\
\hline GeJi9 B-18B & $\mathrm{M}$ & $\mathrm{L}$ & 2.04 \\
\hline GeJi9 B-20 & $\mathrm{F} ?$ & $\mathrm{~L}$ & 1.60 \\
\hline GeJi9 B-26A & M & $\mathrm{L}$ & 2.13 \\
\hline GeJi9 B-26A & $?$ & $\mathrm{R}$ & 1.45 \\
\hline \multicolumn{4}{|l|}{ ULNA } \\
\hline GeJi9 B-3 & $\mathrm{M} ?$ & $\mathrm{~L}$ & 1.58 \\
\hline GeJi9 B-9 & $\mathrm{F}$ & $\mathrm{L}$ & 1.68 \\
\hline GeJi9 B-18B & M & $\mathrm{R}$ & 1.15 \\
\hline GeJi9 B-30 & M & $\mathrm{L}$ & 1.27 \\
\hline \multicolumn{4}{|l|}{ RADIUS } \\
\hline GeJi9 B-9 & $\mathrm{F}$ & $\mathrm{L}$ & 1.48 \\
\hline GeJi9 B-9 & $\mathrm{F}$ & $\mathrm{R}$ & 1.41 \\
\hline GeJi9 B-18B & M & $\mathrm{R}$ & 1.46 \\
\hline
\end{tabular}

buried there. These results advance our knowledge on three distinct fronts: mortuary behaviours at these sites, patterns of 
Table 6 Results of Kruskal-Willis ANOVAs comparing $I_{\max } / I_{\min }$ CSG properties

\begin{tabular}{|c|c|c|c|c|c|}
\hline Element & Sample & $n$ & Mean & S.D. & $p$ value \\
\hline \multirow[t]{5}{*}{ Left humerus } & Cape coast & 75 & 1.56 & 0.20 & \\
\hline & Central interior & 36 & 1.52 & 0.26 & \\
\hline & Namib Desert & 10 & 1.59 & 0.20 & \\
\hline & Pillar Sites & 5 & 1.63 & 0.40 & \\
\hline & & & & & 0.489 \\
\hline \multirow[t]{5}{*}{ Right humerus } & Cape coast & 67 & 1.65 & 0.21 & \\
\hline & Central interior & 32 & 1.51 & 0.23 & \\
\hline & Namib Desert & 12 & 1.64 & 0.20 & \\
\hline & Pillar Sites & 6 & 1.57 & 0.30 & \\
\hline & & & & & 0.764 \\
\hline \multirow[t]{5}{*}{ Femora } & Cape coast & 66 & 1.65 & 0.27 & \\
\hline & Central interior & 47 & 1.41 & 0.24 & \\
\hline & Namib Desert & 17 & 1.40 & 0.27 & \\
\hline & Pillar Sites & 8 & 1.73 & 0.46 & \\
\hline & & & & & 0.000 \\
\hline \multirow[t]{5}{*}{ Tibia } & Cape coast & 44 & 2.46 & 0.44 & \\
\hline & Central interior & 43 & 2.26 & 0.40 & \\
\hline & Namib Desert & 16 & 2.15 & 0.39 & \\
\hline & Pillar Sites & 1 & 2.61 & & \\
\hline & & & & & 0.084 \\
\hline \multirow[t]{3}{*}{ Left clavicle } & Cape coast & 36 & 1.95 & 0.33 & \\
\hline & Pillar Sites & 5 & 1.76 & 0.30 & \\
\hline & & & & & 0.162 \\
\hline \multirow[t]{3}{*}{ Right clavicle } & Cape coast & 41 & 1.85 & 0.40 & \\
\hline & Pillar Sites & 3 & 1.65 & 0.40 & \\
\hline & & & & & 0.321 \\
\hline \multirow[t]{3}{*}{ Left ulna } & Cape coast & 34 & 1.39 & 0.25 & \\
\hline & Pillar Sites & 3 & 1.51 & 0.22 & \\
\hline & & & & & 0.293 \\
\hline \multirow[t]{2}{*}{ Right ulna } & Cape coast & 32 & 1.36 & 0.22 & \\
\hline & Pillar Sites & 1 & 2.04 & & \\
\hline \multirow[t]{3}{*}{ Left radius } & Cape coast & 36 & 1.41 & 0.19 & \\
\hline & Pillar Sites & 1 & 1.48 & & \\
\hline & & & & & 0.757 \\
\hline \multirow[t]{3}{*}{ Right radius } & Cape coast & 33 & 1.51 & 0.22 & \\
\hline & Pillar Sites & 2 & 1.43 & 0.04 & \\
\hline & & & & & 0.659 \\
\hline
\end{tabular}

inter-site variability, and skeletal indicators of health, disease, and mobility among eastern Africa's first herders.

\section{Mortuary patterns at the pillar sites}

Excavations at the four pillar sites west of Lake Turkana lend additional support for the hypothesis that the pillar sites functioned as cemeteries. Building on previous identifications of human remains at Lothagam North and Manemanya, our work has now confirmed the presence of burials in the central platform at Lothagam West, and in potentially younger cairn features at Lothagam West and Kalokol. The presence of a mortuary cavity in Kalokol's platform, beneath a centrally positioned acacia tree, seems possible and may be tested with additional excavations.

The 'Jarigole Mortuary Tradition' can now be revised. Although secondary bundle burials were present within platform deposits at Lothagam North, most interments were primary, as were the few burials excavated at Lothagam West and Manemanya. 'Clothed' bodies, at least with adornments, had been prepared for individual placement. At Lothagam North, both primary and secondary burials were present as discrete features and are likely to have been the source of the isolated fragments found between the bodies within the cobble-filled matrix. None of the western site platforms resemble ossuaries strictly intended for secondary remains, and we did not observe the degree of commingling reported at Jarigole (Nelson 1995). Most human remains recovered from Jarigole are fragments and/or small, mobile elements such as teeth (personal observation, National Museums of Kenya), similar to those observed in the $\sim 50 \mathrm{~cm}$ upper cap deposits at Lothagam North. Future excavations at Jarigole targeting deeper deposits would test the hypothesis that primary burials exist in deeper strata. We do not know whether the architecture of the mortuary cavity and density of burials at Lothagam North are typical. Although multiple burials were encountered at Lothagam West and Manemanya, neither site presented the deeply stratified mortuary deposits observed at Lothagam North (Fig. 5).

Based on available evidence, pillar sites are cemeteries, although the extent to which this was their primary function remains unclear. Most of the burials are primary, indicating that people were brought to the site shortly after death, contradicting previous notions. This fact raises additional questions about mobility, social organization, and funerary practices among groups who used these sites. Was each pillar site used by a specific group and/or extended family who either lived nearby or travelled great distances immediately after a death? Or were individuals interred based on when and where they died or some combination of other factors? Why were some people included as secondary burials? And did funerals trigger large community gatherings or were they smaller affairs carried out by a subset of relatives? To answer these questions, we need more information about who was buried at specific pillar sites and in what contexts. As research to date has focused largely on Lothagam North, future excavations should target other sites, particularly Kalokol and Manemanya, to probe patterns of mortuary variation.

\section{Intra-site variability: personal adornment}

Although material culture varies among the western pillar sites (Grillo and Hildebrand 2013; Hildebrand et al. 2011), 

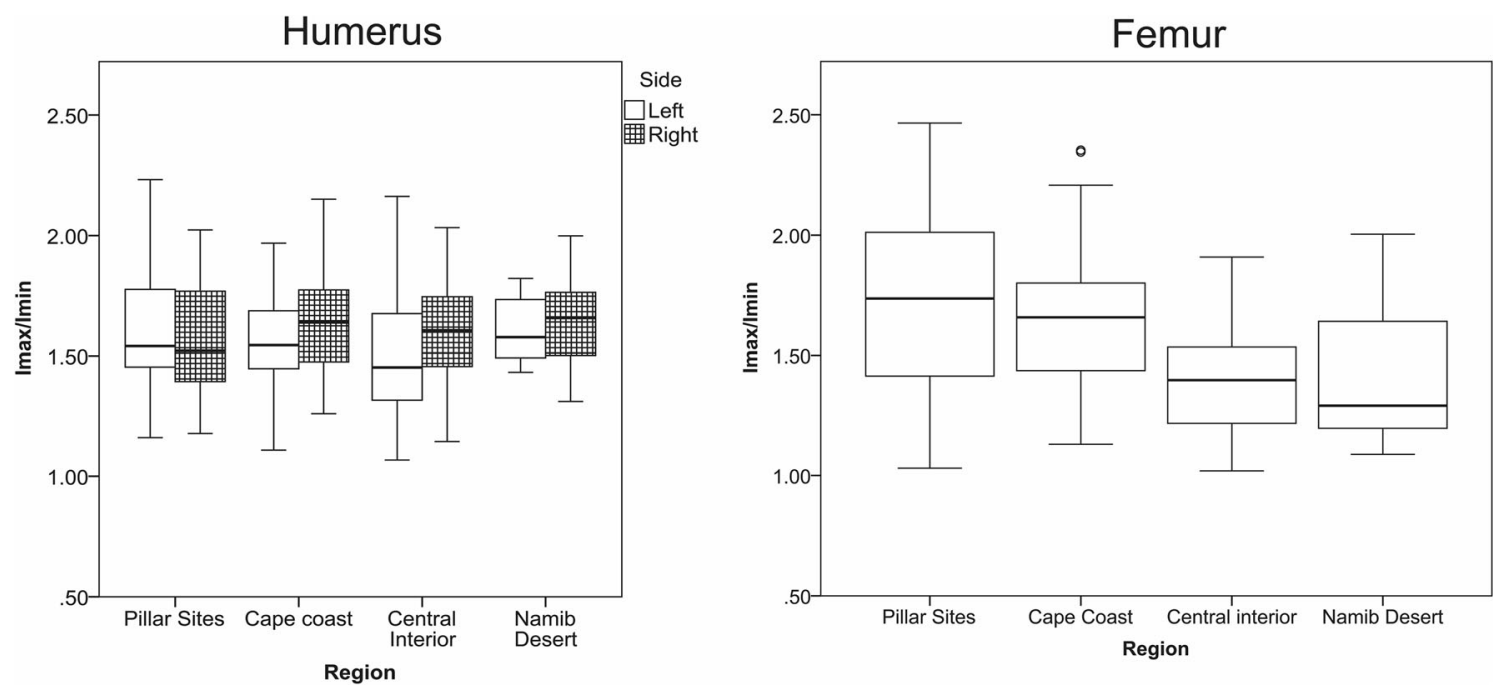

Fig. $8 \mathrm{CSG} I_{\max } / I_{\min }$ ratios for humerus and femur midshafts for the pillar site sample compared to southern African Later Stone Age Cape Coastal, Central Interior, and Namib Desert foragers and herders

bioarchaeological excavations add another layer of complexity: items directly associated with buried people. With a few potential exceptions, such as the bone and ivory object at Manemanya and the zoomorphic palette at Lothagam North, all examples appear to be adornments rather than burial gifts. At Lothagam North, stone beads were associated with most primary burials in the central platform in diverse combinations of number, raw material, and colour (Figs. 5 and 6, Table 2). Although some of the stones may have originated nearby, others would have come from more distant and distinct sources. Beads were found with men, women, and children, and they varied in pattern from person to person. Burials that could not be associated with any ornamentation were also the most incomplete and poorly preserved, so may have been associated with other beads found in the platform fill. The ubiquity of beads with the burials suggests that interment with adornment was the norm. Patterns of bead distribution, combined with the presence of men, women, and children within the central platform, suggests minimal social stratification among people buried there (Hildebrand et al. 2018).

The elaborate burial encountered at Manemanya (GcJh5 B-1) may reflect unique circumstances. The unidentified items lain to her right and the strands of beads strewn on her body after interment distinguish this burial from those at Lothagam North, where almost all adornments could have been worn by the deceased. The hundreds of stone beads and thousands of OES beads covering her body may signify special status or identity within the group. Stone bead raw materials are quite different from those observed at Lothagam North and Jarigole. Calcite and sandstone that would have been readily available from local sources are dominant at Manemanya. Other ornaments, such as the perforated lion tooth pendant, were likely difficult to procure, suggesting her bead choices may have been stylistic rather than economic. Future excavations at
Manemanya may reveal whether this burial's degree and types of ornamentation were exceptional or the norm.

Bead and other burial inclusion differences between Lothagam North and Manemanya, and between these sites and Lothagam West and Kalokol (where few to no beads were recovered) are topics that merit further investigation. Grillo and Hildebrand (2013) note that differences between pillar sites do not easily track with geography or time; Lothagam North and Jarigole are the most artifactually similar despite their positions on opposite sides of the lake $(\sim 300 \mathrm{~km}$ apart by land and $\sim 100 \mathrm{~km}$ by water), while Lothagam North and West are quite different despite close proximity and evidence of use within the same 60-year period. Because it can be assumed that the people using the two contemporaneous pillar sites on Lothagam were aware of each other, differences in material culture must reflect some other aspect of function, identity, or preference. That said, some aspects of this tradition could well have shifted over the centuries-long span of pillar site activity, and later burial events may reflect very different dynamics and social organisation those from earlier times.

\section{Skeletal indicators for health, disease, and activity}

This new skeletal sample represents one of the largest collections from across eastern Africa, and the only one known to represent the region's earliest food producers. Bioarchaeological datasets provide a first glimpse into who was buried at the pillar sites and their lived experiences. Burials at Lothagam North seemingly represent a crosssection of a community in terms of age and sex, suggesting most members of the group may have been buried there. While excavations at the other sites have been more minimal, the cairn burial of a child at Lothagam West and heavily ornamented young woman at Manemanya raise other 
questions about early herder social organization. Circumstances leading to burial within a pillar site remain an ongoing topic of investigation.

Skeletal analyses provide several insights into the lives of these individuals. Prevalent conditions like OA suggest that people were living many years into adulthood, and evidence for more serious diseases and/or traumatic injuries is rare. However, systematic assessments were limited by the fragmentary nature of the remains, particularly the crania which were often crushed by a heavy boulder or slab. Dental health was relatively good with slight wear and low rates of caries, but a high prevalence of dental calculus. A non-cariogenic diet low in carbohydrates seems to have been more influential in deterring carious lesions than rapid tooth wear or cleaning (for which there is no evidence). Most individuals exhibit enamel hypoplasias suggesting some health stressors during development. LEH rates are likely underestimates as the teeth were too fragile to cast for microscopic study; future work will require a novel approach.

Limb CSG properties fall within the range of southern African foragers whose subsistence patterns required them to move frequently across the landscape. Upper $\operatorname{limb} I_{\max } / I_{\min }$ values suggest that early herder lifeways around Lake Turkana required similar types of limb activities as those used by prehistoric southern African populations, although this cannot be associated with a specific activity or movement type. Southern African forager upper limb CSG properties differ from those of contemporary swimmers (Shaw and Stock 2013), as well as from archaeological groups who engaged in watercraft use (Stock and Pfeiffer 2001). Comparable upper limb morphologies suggest that the people at the pillar sites around Lake Turkana likely did not engage in heavy use of watercraft (i.e. paddling) or frequent bouts of vigorous swimming to obtain freshwater resources.

There are significant differences between the femur $I_{\max } /$ $I_{\min }$ values among the four groups, although no pairwise differences reach significance. Pillar site femur $I_{\max } / I_{\min }$ values are higher than Central Interior and Namib Desert values, and most similar to those of Cape Coast foragers (Fig. 8). Greater lower limb $I_{\max } / I_{\min }$ values have been associated with mobility across complex (but not necessarily high relief) terrain (Higgins 2014), as well as unidirectional lower limb movement, such as those undertaken by marathon runners (Shaw and Stock 2009). Although both factors are known to produce high $I_{\max } / I_{\min }$ ratios, it is not possible to determine which factor was the primary driver in archaeological samples. Among the Cape Coast foragers, high values are attributed to an intensive mobile foraging lifestyle in a region with complex terrain, including rocky shorelines (Stock and Pfeiffer 2004; Cameron and Stock 2018). Slightly lower values among Coastal Interior and Namib Desert groups likely reflect high mobility but on less-complex landscapes (Cameron and Stock 2018). Similarities between the pillar site sample and Cape
Coast foragers can be interpreted in two ways: either early herders around Lake Turkana moved across comparably complex (but not necessarily similar) terrain or their terrestrial mobility patterns were sufficiently intense to produce an equivalently high signal. These possibilities provide a starting point for further study of mid-Holocene Turkana landscapes and how people were moving across them. However, interpretation is limited by the small number of skeletons that were complete enough to assess for CSG properties, as well as the lack of eastern African comparative samples.

It is difficult to contextualize those buried at the pillar sites among other human populations because we know little about the health of ancient herders or forager societies transitioning to mobile pastoralism. Research on contemporary African pastoralists facing sedentarisation suggests that nomadic groups maintain lower levels of malnutrition and morbidity than settled groups, although this is complicated by other factors such as access to medical care (Fratkin and Abella Roth 2005). Some attributes of the western pillar site sample, such as their low rates of dental caries and infectious disease, may indicate similar diet and health patterns between ancient and contemporary mobile pastoralists in eastern Africa. Skeletal evidence consistent with high mobility and/or mobility across complex terrain suggests other potential parallels. Ongoing bioarchaeological work at the pillar sites, as well as fisherforager sites in Turkana such as Lothagam Lokam (Goldstein et al. 2017), may provide additional insights into the biocultural impacts of the transition to herding as well as permit comparisons of health and behaviour between past vs. present-day pastoralists.

\section{Conclusions}

Bioarchaeological investigations at four megalithic pillar sites west of Lake Turkana have revealed important information on the behaviour and biology of the first herders in eastern Africa. Our findings confirm some previous assumptions about this mortuary tradition and challenge others. All pillar sites do appear to have mortuary components, and at least one (Lothagam North) likely accommodated hundreds of people. However, most burials on the west side of Lake Turkana are primary. This indicates that people were usually buried shortly after death rather than receiving prior treatment and subsequent inclusion as secondary burials (although both types of burial are present at Lothagam North). Further work is needed to discern whether primary burials predominate in deeper deposits at pillar sites on the east side of the lake, and the extent of mortuary deposits at Lothagam West, Manemanya, and Kalokol.

Stone and OES beads recovered from Lothagam North are similar to those previously excavated from Jarigole, but at Lothagam North, their function as adornments within primary 
interments is clear. The presence of beads with most burials, without apparent patterning regarding age and sex, suggests the absence of strong social hierarchies (Hildebrand et al. 2018). However, an elaborate burial excavated from Manemanya with thousands of beads, many of types distinct from those at Lothagam North, raises additional questions about material cultural variability among pillar sites and the complexity of social roles within these communities. As pillar sites represent a globally rare example of monumentality among mobile herders in unpredictable circumstances, beads and other artefacts provide important clues about the social processes and institutions that helped people manage risk.

Beyond mortuary and material culture insights, this work has yielded a unique collection of archaeological human remains from an early food-producing society in Africa. Little is known about human populations from this region and time period, or about groups transitioning from fishing and foraging to mobile herding. Regional consequences of the shift to food production have long been a topic of bioarchaeological inquiry, but few studies have focused on early pastoralism given a lack of suitable skeletal samples in Africa and beyond. Human remains from the pillar sites provide a record of people who lived through major environmental and economic shifts, permitting us to explore their dynamic social responses. Not only do monumental cemeteries around Lake Turkana capture a key time period in eastern Africa, they offer important perspectives on how humans react and adapt to significant changes in the world around them.

Acknowledgements We thank the people of Turkana County, the National Museums of Kenya, and Kenya's National Council of Science and Technology for the permission to conduct research. LPWT crew members who assisted with excavations include P. Adupu, S. Derbyshire, A. DeRenzis, L.E. Doyle, H. Duke, M. Ekaale, M. Eyane, F. Ekai, J. Ekusi, A. Ekutaan, J. Etabo, L. Hu, B. Kimeu, L. Lowasa, Z. McKeeby, C. Ngugi, S. Pilliard, M. Rizzo, H. Sale, A. Shoemaker, B. Smith, and C. Swoger. We also thank project collaborators Emmanuel Ndiema, Purity Kiura, and Cecelia Ngugi. Figures 3 and 4 were adapted from maps produced by Benson Kimeu. Justus Erus Edung (of the National Museums of Kenya-Lodwar Office) helped ensure maximal recovery of looted remains from the Kalokol Pillar Site. The Turkana Basin Institute provided crucial logistical support throughout this research.

Funding information Open access funding provided by Max Planck Society. Funding was provided by the National Geographic Society (CRE9473-14 to EAH in 2014), the National Science Foundation (Grant BCS1124419 to EAH in 2012-2016), the Wenner-Gren Foundation (Grant 58962 to CEK in 2015), and the Social Sciences and Humanities Research Council of Canada (767-2012-1903 to EAS in 2012).

Open Access This article is distributed under the terms of the Creative Commons Attribution 4.0 International License (http:// creativecommons.org/licenses/by/4.0/), which permits unrestricted use, distribution, and reproduction in any medium, provided you give appropriate credit to the original author(s) and the source, provide a link to the Creative Commons license, and indicate if changes were made.

\section{References}

AlQahtani SJ, Hector MP, Liversidge HM (2010) Brief communication: the London atlas of human tooth development and eruption. Am J Phys Anthropol 142:481-490

Auerbach BM, Ruff CB (2006) Limb bone bilateral asymmetry: variability and commonality among modern humans. J Hum Evol 50(2): 203-218

Barthelme JW (1977) Holocene sites north of Lake Turkana. Azania 12: 33-42

Barthelme JW (1985) Fisher-hunters and Neolithic pastoralists in East Turkana, Kenya, British Archaeological Reports International Series 254. Archaeopress, Oxford

Buikstra JE, Ubelaker DH (1994) Standards for data collection from human skeletal remains. Arkansas Archaeological Survey Research Series, Fayetteville

Cameron ME, Pfeiffer S (2014) Long bone cross-sectional geometric properties of Later Stone Age foragers and herder-foragers. S Afr J Sci 110:1-11

Cameron ME, Stock JT (2018) Ecological variation in Later Stone Age southern African biomechanical properties. J Archaeol Sci Rep 17: $125-136$

Chritz KL, Cerling TE, Freeman KH, Hildebrand EA, Janzen A, Prendergast ME (2019) Climate, ecology, and the spread of herding in eastern Africa. Quat Sci Rev 204:119-132

Davies TG, Shaw CN, Stock JT (2012) A test of a new method and software for the rapid estimation of cross-sectional geometric properties of long bone diaphyses from 3D laser surface scans. Archaeol Anthropol Sci 4:277-290

Fratkin E, Abella Roth E (2005) As pastoralists settle: social, health, and economic consequences of pastoral sedentarization in Marsabit District, Kenya. Kluwer, New York

Garcin Y, Melnick D, Strecker MR, Olago D, Tiercelin J-J (2012) East African mid-Holocene wet-dry transition recorded in palaeoshorelines of Lake Turkana, northern Kenya rift. Earth Planet Sc Lett 331-332:322-334

Gifford-Gonzalez D (2017) “Animal disease challenges" fifteen year later: the hypothesis in light of new data. Quat Int 436:283-293

Githinji CK (1999) Il Lokeridede: a Pastoral Neolithic mortuary site east of Lake Turkana, Kenya. Unpublished MA thesis, University of Nairobi

Goldstein ST (In Press) Technological strategies of the earliest herders in northern Kenya. Antiquity

Goldstein ST, Hildebrand EA, Storozum MJ, Sawchuk EA, Lewis JE, Ngugi C, Robbins LH (2017) New archaeological investigations at the Lothagam harpoon site at Lake Turkana. Antiquity 91 360:e5:1e5:5. https://doi.org/10.15184/aqy.2017.215

Grillo KM, Hildebrand EA (2013) The context of early megalithic architecture in eastern Africa: the Turkana Basin c. 5000-4000 BP. Azania 48:193-217

Gwynne MD (1969) The South Turkana expedition: scientific papers. Preliminary report on the 1968 season. Geogr J 135:331-342

Higgins RW (2014) The effects of terrain on long bone robusticity and cross- sectional shape in lower limb bones of bovids, Neandertals, and Upper Paleolithic modern humans. In: Carlson KJ, Marchi D (eds) Reconstructing mobility: environmental, behavioural, and morphological determinants. Springer, New York, pp 227-252

Hildebrand EA, Grillo KM (2012) Early herders and monumental sites in eastern Africa: dating and interpretation. Antiquity 86:338-352

Hildebrand EA, Shea J, Grillo KM (2011) Four middle Holocene pillar sites in West Turkana, Kenya. J Field Archaeol 36:181-200

Hildebrand EA, Grillo KM, Sawchuk EA, Pfeiffer SK, Conyers LB, Goldstein ST, Hill AC, Janzen A, Klehm CE, Helper M, Kiura P, Ndiema E, Ngugi C, Shea JJ, Wang H (2018) A monumental 
cemetery built by eastern Africa's first herders near Lake Turkana, Kenya. Proc Natl Acad Sci U S A 115(36):8942-8947

Hillson S (2005) Teeth, 2nd edn. Cambridge University Press, Cambridge Kamau J (1991) Report on "stone pillar" site north of Jarigole Burial Mound, East Turkana. Nyame Akuma 36:6-7

Koch CP (1993) Koobi Fora Holocene archaeology and skeletal biology project. Unpublished interim 1993 report to the office of the president, Nairobi, Kenya

Koch CP (1994) The Jarigole mortuary tradition: new light on Pastoral Neolithic burial practices. Paper presented at the 16th meeting of the South African Archaeological Association, Pietermaritzburg, South Africa

Koch CP, Pavlish LA, Farquhar RM, Hancock RGV, Beukens RP (2002) INAA of pottery from Il Lokeridede and Jarigole, Koobi Fora, Kenya. In: Jerem E, Biro KT (eds) Archaeometry 98: proceedings of the 31st symposium. Archaeopress, Budapest, pp 587-592

Lewis ME (2004) Endocranial lesions in non-adult skeletons: understanding their aetiology. Int J Osteoarchaeol 14:82-97

Lynch BM (1978) The Namoratunga cemetery and rock art sites of N.W. Kenya: a study of early pastoral social organization. Unpublished $\mathrm{PhD}$ dissertation, Michigan State University

Lynch BM, Robbins LH (1978) Namoratunga: the first archaeoastronomical evidence in sub-Saharan Africa. Science 200: 766-768

Lynch BM, Robbins LH (1979) Cushitic and Nilotic prehistory: new archaeological evidence from NW Kenya. J Afr Hist 20:319-328

Macintosh AA, Davies TG, Ryan TM, Shaw CN, Stock JT (2013) Periosteal versus true cross-sectional geometry: a comparison along humeral, femoral, and tibial diaphyses. Am J Phys Anthropol 150: $442-452$

Marshall F, Stewart K, Barthelme J (1984) Early domestic stock at Dongodien in northern Kenya. Azania 19:120-127

McHenry HM (1992) Body size proportions in early hominids. Am J Phys Anthropol 87:407-431

Meadows L, Jantz RL (1992) Estimation of stature from metacarpal lengths. J Forensic Sci 37:147-154

Ndiema EK, Dillian CD, Braun DR, Harris JWK, Kiura PW (2011) Transport and subsistence patterns at the transition to pastoralism, Koobi Fora, Kenya. Archaeometry 53:1085-1098

Nelson CM (1995) The work of the Koobi Fora field school at the Jarigole Pillar Site. Kenya Past and Present 27:49-63

Nilesh K, Mukherji S (2013) Congenital muscular torticollis. Ann Maxillofac Surg 3(2):198-200

Robbins LH (1972) Archaeology in the Turkana District, Kenya. Science 176:359-366

Ruff CB. (2006) MomentMacro for NIH Image and Image J. Available at: http://www.hopkinsmedicine.org/fae/mmacro.html. Accessed May 2015

Ruff CB (2008) Biomechanical analyses of archaeological human skeletons. In: Katzenberg MA, Saunders SR (eds) Biological anthropology of the human skeleton, 2nd edn. Wiley-Liss, Inc., New York, pp 183-206

Ruff CB, Scott WW, Liu AY (1991) Articular and diaphyseal remodeling of the proximal femur with changes in body mass in adults. Am J Phys Anthropol 86:397-413
Sawchuk EA (2017) Social change and human population movements dental morphology in Holocene eastern Africa. Unpublished $\mathrm{PhD}$ dissertation, University of Toronto

Sawchuk EA, Goldstein ST, Grillo KM, Hildebrand EA (2018) Cemeteries and the spread of pastoralism from the Sahara through eastern Africa. J Anthropol Archaeol 51:187-205

Shaw CN, Stock JT (2009) Intensity, repetitiveness, and directionality of habitual adolescent mobility patterns influence the tibial diaphysis morphology of athletes. Am J Phys Anthropol 140:149-159

Shaw CN, Stock JT (2013) Extreme mobility in the Late Pleistocene? Comparing limb biomechanics among fossil Homo, varsity athletes and Holocene foragers. J Hum Evol 64:242-249

Smith BH (1984) Patterns of molar wear in hunter-gatherers and agriculturalists. Am J Phys Anthropol 63:39-56

Soper R (1982) Archaeo-astronomical Cushites: some comments. Azania 17:145-162

Soper R, Lynch M (1977) The stone circle graves at Ng'amoritung'a, southern Turkana district, Kenya. Azania 12:193-208

Stock JT, Pfeiffer S (2001) Linking structural variability in long bone diaphyses to habitual behaviours: foragers from the southern African Later Stone Age and the Andaman Islands. Am J Phys Anthropol 115:337-348

Stock JT, Pfeiffer SK (2004) Long bone robusticity and subsistence behaviour among Later Stone Age foragers of the forest and fynbos biomes of South Africa. J Archaeol Sci 31:999-1013

Stock JT, Shaw CN (2007) Which measures of diaphyseal robusticity are robust? A comparison of external methods of quantifying the strength of long bone diaphyses to cross-sectional geometric properties. Am J Phys Anthropol 134:412-423

Thiesen G, Gribel BF, Freitas MP (2015) Facial asymmetry: a current review. Dent Press J Orthod 20:110-125

Trotter M (1970) Estimation of stature from intact long bones. In: Steward TD (ed) Personal identification in mass disasters. Smithsonian Institution Press, Washington, DC, pp 71-83

Trotter M, Gleser GC (1952) Estimation of stature from long bones of American Whites and Negroes. Am J Phys Anthropol 10(4):463514

Turner CG, Nichol CR, Scott GR (1991) Scoring procedures for key morphological traits of the permanent dentition: the Arizona State University dental anthropology system. In: Kelley MA, Larsen CS (eds) Advances in dental anthropology. Wiley-Liss, New York, pp 13-32

White TD, Black MT, Folkens PA (2011) Human osteology, 3rd edn. Elsevier Academic Press, Cambridge

Williamson RF, Clish A, Clark GR, Pfeiffer S (2003) The archaeology of the Moatfield ossuary. In: Williamson RF, Pfeiffer S (eds) Bones of the ancestors: the archaeology and osteobiography of the Moatfield Site. Archaeological Survey of Canada Mercury Series Paper, vol 163. Canadian Museum of Civilization, Ottawa, pp 133-162

Publisher's note Springer Nature remains neutral with regard to jurisdictional claims in published maps and institutional affiliations. 